\title{
Bax Contributes to Retinal Ganglion Cell Dendritic Degeneration During Glaucoma
}

\author{
Michael L. Risner ${ }^{1} \cdot$ Silvia Pasini $^{1} \cdot$ Nolan R. McGrady $^{1} \cdot$ David J. Calkins $^{1}$ D
}

Received: 12 August 2021 / Accepted: 30 November 2021 / Published online: 5 January 2022

(C) The Author(s) 2021

\begin{abstract}
The BCL-2 (B-cell lymphoma-2) family of proteins contributes to mitochondrial-based apoptosis in models of neurodegeneration, including glaucomatous optic neuropathy (glaucoma), which degrades the retinal ganglion cell (RGC) axonal projection to the visual brain. Glaucoma is commonly associated with increased sensitivity to intraocular pressure (IOP) and involves a proximal program that leads to RGC dendritic pruning and a distal program that underlies axonopathy in the optic projection. While genetic deletion of the Bcl2-associated X protein $\left(\mathrm{Bax}^{-/}\right)$prolongs RGC body survival in models of glaucoma and optic nerve trauma, axonopathy persists, thus raising the question of whether dendrites and the RGC light response are protected. Here, we used an inducible model of glaucoma in $\mathrm{Bax}^{-/-}$mice to determine if $\mathrm{Bax}$ contributes to RGC dendritic degeneration. We performed whole-cell recordings and dye filling in RGCs signaling light onset $(\alpha \mathrm{ON}$ Sustained) and offset ( $\alpha$ OFF-Sustained). We recovered RGC dendritic morphologies by confocal microscopy and analyzed dendritic arbor complexity and size. Additionally, we assessed RGC axon function by measuring anterograde axon transport of cholera toxin subunit B to the superior colliculus and behavioral spatial frequency threshold (i.e., spatial acuity). We found 1 month of IOP elevation did not cause significant RGC death in either WT or Bax ${ }^{-/-}$retinas. However, IOP elevation reduced dendritic arbor complexity of WT $\alpha \mathrm{ON}$-Sustained and $\alpha \mathrm{OFF}-$ Sustained RGCs. In the absence of Bax, $\alpha \mathrm{ON}$ - and $\alpha \mathrm{OFF}-$ Sustained RGC dendritic arbors remained intact following IOP elevation. In addition to dendrites, neuroprotection by $\mathrm{Bax}^{-/-}$generalized to $\alpha \mathrm{ON}$-and $\alpha \mathrm{OFF}-$ Sustained RGC light- and current-evoked responses. Both anterograde axon transport and spatial acuity declined during IOP elevation in WT and $\mathrm{Bax}^{-{ }_{-}}$mice. Collectively, our results indicate Bax contributes to RGC dendritic degeneration and distinguishes the proximal and distal neurodegenerative programs involved during the progression of glaucoma.
\end{abstract}

Keywords Bcl2-associated X protein $\cdot \mathrm{Bax}^{-/-} \cdot$ Neuroprotection $\cdot$ Neurodegeneration $\cdot$ Glaucoma $\cdot$ Retinal ganglion cells . Dendritic morphology $\cdot$ Axonopathy

\section{Abbreviations \\ RGC Retinal ganglion cells \\ IOP Intraocular pressure}

David J. Calkins

david.j.calkins@vumc.org

Michael L. Risner

michael.1.risner@vumc.org

Silvia Pasini

s.pasini3@gmail.com

Nolan R. McGrady

nolan.mcgrady@vumc.org

1 Vanderbilt Eye Institute, Department of Ophthalmology and Visual Sciences, Vanderbilt University Medical Center, AA7103 MCN/VUIIS, 1161 21st Ave. S., Nashville,

TN 37232, USA
WT Wild type

Bcl-2 B-cell lymphoma 2

Bax Bcl-2-associated $\mathrm{X}$ protein

Brn3a Pou domain, class 4, transcription factor 1

SMI-32 Non-phosphorylated neurofilament H

RMP Resting membrane potential

IPL Inner plexiform layer

CTB Cholera toxin subunit B

ChAT Choline acetyltransferase

SC Superior colliculus 


\section{Background}

The BCL-2 (B-cell lymphoma-2) family of proteins contributes broadly to intrinsic, mitochondrial-based, apoptosis during development, cancer, and neurodegeneration [1]. During neurodegeneration, chronic cellular stress initiates apoptosis through the activation of Bcl-2-associated $\mathrm{X}(\mathrm{BAX})$ protein [1]. Upon activation, BAX proteins translocate from the cytosol to the mitochondrial outer membrane [2]. Within the mitochondrial outer membrane, BAX form heterodimers with BCL-2-antagonist/killer (BAK) or homodimers with other BAX proteins [3, 4]. Dimerization facilitates the formation of BAX oligomers [5] that permeabilize the mitochondrial outer membrane, causing the release of cytochrome $c$ and second mitochondrial-derived activator of caspases (SMAC) into the cytosol, promoting cell death $[6,7]$.

Genetic deletion of $\operatorname{Bax}\left(\mathrm{Bax}^{-1-}\right)$ prevents cell death in affected tissues in models of neurodegeneration, including Parkinson's disease [8], Alzheimer's disease [9], amyotrophic lateral sclerosis [10], and glaucomatous optic neuropathy (glaucoma) [1, 11]. Glaucoma typically presents as an age-related neurodegenerative disease piqued by sensitivity of visual tissues to intraocular pressure (IOP). Glaucoma causes neurological blindness by targeting retinal ganglion cells (RGC) and their axons for degeneration through two main programs: a distal program in the optic nerve proper, affecting RGC axons, and a proximal program in the retina, affecting RGC somas, dendrites, and synapses [11-13]. Evidentiary support for compartmentalized neurodegeneration comes from inducible and chronic genetic models of glaucoma combined with gene or pharmaceutic dosing [13-20]. Neuroprotection of axons by administering nicotinamide and/or expressing the slow Wallerian degeneration $\left(W l d^{\mathrm{S}}\right)$ allele reduces axon dropout, preserves anterograde axon transport, and protects spatial acuity, but somatic and dendritic degeneration persists $[17-19,21,22]$. Bax $^{-/}$proves protective against RGC body death in models of glaucoma and acute focal injury to the optic nerve, yet axons comprising the optic nerve still undergo significant degeneration [14, 23].

Genetic and inducible models of glaucoma combined with genetic dosing of Bax and Wld ${ }^{\mathrm{S}}$ elegantly demonstrate compartmentalized degeneration [11, 12, 18, 22]. Here, we sought to investigate the influence of $\mathrm{Bax}^{-/-}$on RGC dendrites and signaling prior to significant cell death. Using an inducible microbead model of glaucoma [24], we found Bax contributes to dendritic pruning and degradation of evoked responses of alpha RGCs signaling light increments $(\alpha \mathrm{ON}$-Sustained) and decrements ( $\alpha \mathrm{OFF}$ Sustained). IOP elevation decreased anterograde axonal transport and spatial acuity during glaucoma in both WT and $\mathrm{Bax}^{-/-}$animals. Our results indicate Bax contributes to the reduction in RGC dendritic complexity and signaling during IOP elevation and illustrates the separability of the proximal and distal programs involved in degeneration during glaucoma.

\section{Methods}

\section{Animals and Genotype Confirmation}

All experimental procedures were approved by the Vanderbilt University Institutional Animal Care and Use Committee. We obtained 6- to 8-week-old male C57B1/6 (WT) mice from Charles River Laboratory (Wilmington, MA). We obtained 4- to 10-week-old male mice with a targeted null mutation in the Bax gene (Bax ${ }^{-/-}, 002994$ - B6.129X1$B a x^{t m l S j k}$ ) from Jackson Laboratory (Bar Harbor, ME, [25]), We confirmed $\mathrm{Bax}^{-/-}$by PCR according to the vendor's protocol, using the following primers: GTT GAC CAG AGT GGC GTA GG (Common), CCG CTT CCA TTG CTC AGC GG (Mutant forward), and GAG CTG ATC AGA ACC ATC ATG (WT forward). We obtained primers from Integrated DNA Technologies (Coralville, IA). Mice were maintained on a 12-h light-dark cycle with standard rodent chow and water available as desired.

\section{IOP Elevation and Measurement}

We anesthetized mice with isoflurane (2.5\%), and we applied tropicamide (1\%), proparacaine $(0.5 \%)$, and lubricating drops to both eyes. We unilaterally elevated IOP by injecting $1.5 \mu \mathrm{L}$ of $15-\mu \mathrm{m}$ polystyrene microbeads (Invitrogen, Carlsbad, CA) into the anterior chamber of the eye via a borosilicate glass pipette attached to a micromanipulator (M3301R, WPI, Sarasota, FL) driven by a microsyringe pump (DMP, WPI, Sarasota, FL, [24]). For an internal control, we injected an equal volume of sterile phosphate-buffered saline (PBS) into the fellow eye. As previously described [24, 26-28], we measured IOP in anesthetized (2.5\% isoflurane) mice by rebound tonometry (Tono-Pen XL, Reichert Technologies, Depew, NY). We measured baseline IOP of each eye 1 week before microbead/saline injection. After injections, we measured IOP at least 2 times per week for 1 month.

\section{Retinal Ganglion Cell Physiology}

We performed whole-cell current-clamp ( $0 \mathrm{pA})$ recordings from RGCs in whole-mount retinas, using previously established protocols from our laboratory [27-29]. Whole retinas were removed from eyes and placed in a physiologic chamber. Retinas were continuously perfused at a rate of $2 \mathrm{~mL} / \mathrm{min}$ with carbogen-saturated $\left(95 \% \mathrm{O}_{2}, 5 \%\right.$ 
$\mathrm{CO}_{2}$ ) bicarbonate-buffered Ames' media supplemented with glucose $(20 \mathrm{mM})$ heated to $32^{\circ} \mathrm{C}$ (Model TC-344C, Warner Instruments, Hamden, CT). Extracellular solution pH was 7.4 and osmolarity 290 (Vapro 5600, Wescor Inc., Logan, UT). Whole-cell recordings were performed using borosilicate pipettes filled with (in $\mathrm{mM}$ ): $125 \mathrm{~K}$-gluconate, $10 \mathrm{KCl}, 10$ HEPES, 10 EGTA, $4 \mathrm{Mg}$-ATP, $1 \mathrm{Na}-\mathrm{GTP}$, and 0.1 ALEXA 555 (Invitrogen, Carlsbad, CA). Intracellular solution $\mathrm{pH}$ was 7.35 and osmolarity was 285 . When filled with intracellular solution, pipette resistance was 4-8 $\mathrm{M} \Omega$. Electrical signals were amplified and sampled at $\geq 10 \mathrm{kHz}$ (Multiclamp 700B, Digidata 1550A, Molecular Devices, San Jose, CA).

During whole-cell current-clamp recordings, we targeted alpha-type RGCs. For $70 \%$ of cells analyzed (256 out of 364), we determined the distance from the optic nerve head. On average, cells were in the mid peripheral retina. We tested RGC responses to light and current injections ( 0 to $180 \mathrm{pA}$ in $20 \mathrm{pA}$ increments). Light responses were evoked by a light-emitting diode system (pE-4000, CoolLED, Andover, UK), and light was focused onto the retina through the microscope objective (40×, full field, $365 \mathrm{~nm}, 3 \mathrm{~s}$ ). After physiology, retinas were fixed overnight in $4 \%$ paraformaldehyde (PFA) at $-4^{\circ} \mathrm{C}$. The following day, the PFA solution was removed and substituted with PBS, and we prepared retinas for immunohistochemistry.

\section{Retinal Immunohistochemistry, Imaging, and Dendritic Morphologic Analysis}

We performed immunohistochemistry on whole-mount retinas and sections from superior colliculus (SC) as previously described [26, 27, 29-31]. Retinas were immunolabeled with the following primary antibodies: mouse-non-phosphorylated neurofilament H (SMI-32,1:1000; 801701, BioLegend, San Diego, CA) and goat-choline acetyltransferase (ChAT, AB144P,1:100, Millipore, Burlington, MA). For a subset of experiments, we determined the density of RGCs in WT and $\mathrm{Bax}^{-/}$whole mount retinas by immunolabeling against mouse-SMI-32 (1:1000; 801701, BioLegend, San Diego, CA) and goat-Brn3a (1:200, Santa Cruz Biotechnology, Dallas, TX). For SMI-32-positive and Brn3a-positive cell counts, confocal micrographs were taken with an Olympus FV1000 using a $60 \times$ objective. Four images were taken within each quadrant (superior, inferior, nasal, temporal) of the retina. Cell counts were performed manually by a masked investigator and then averaged. SMI-32 intensity was determined by creating ROIs around the soma of each SMI-32-positive cell and normalizing to background. We determined neuronal density in SC sections by immunolabeling against rabbit-NeuN (1:500,12943, Cell Signaling Technology, Danvers, MA). Z-stack images were obtained using a $40 \times$ objective with a $2 \times$ zoom. Max intensity projections were generated for each z-stack and NeuN-positive cell counts were performed manually by a masked investigator.

We imaged tissues using confocal microscopy (Olympus FV-1000). RGC dendritic arbors were montaged and manually traced using Adobe Illustrator and Adobe Photoshop, respectively. Skeletonized dendritic arbors were analyzed using Fiji (ImageJ, version 1.53c). We determined the dendritic field area using the polygon selection tool in Fiji. We determined dendritic branch points by manually counting the number of dendritic bifurcations [22, 26]. Sholl analysis was performed using the Fiji plugin. For dendritic depth, we measured the distance from the start of the IPL to the inner most dendritic fluorescence signal. Six distance measurements were taken for each cell with regard to total IPL and dendritic depth, and then averaged. Dendritic depth was presented as a percentage of the relative total IPL depth for each cell.

\section{Anterograde Axonal Transport Analysis}

Mice were anesthetized with isoflurane (2.5\%), and we injected $1 \mu \mathrm{L}$ of cholera toxin subunit B 488 (CTB-488, Molecular Probes, Eugene, OR) into the anterior chamber of both eyes [26, 27, 29, 32]. We allowed 2 days for transport of CTB-488 to the SC. After this time, we perfused mice transcardially with PBS followed by 4\% PFA. After perfusion, we removed brains and cryoprotected them in sucrose (30\%). We then obtained coronal midbrain sections $(50 \mu \mathrm{m})$ using a freezing sliding microtome. After sectioning, alternating $\mathrm{SC}$ sections were mounted and imaged using a Nikon $\mathrm{Ti}$ Eclipse microscope (Nikon Instruments Inc., Melville, NY). We quantified the area of CTB-488 signal (intact transport) using a custom-written routine in ImagePro (Media Cybernetics, Bethesda, MD, [31]). Heat map surface plots show the fluorescence area relative to the total area of the SC. We confirmed successful CTB-488 uptake by RGCs in wholemount retinas by confocal microscopy.

\section{Optic Nerve Transmission Electron Microscopy and Optic Nerve Axon Quantification}

One month after IOP elevation, we perfused WT and $\mathrm{Bax}^{-1-}$ mice with $0.1 \mathrm{M}$ cacodylate buffer followed by $2.5 \%$ glutaraldehyde in cacodylate buffer. We carefully removed eyes with the optic nerve attached. We then isolated 3-mm segments of optic nerve proximal to the globe and post-fixed them for $1 \mathrm{~h}$ in $2.5 \%$ glutaraldehyde in cacodylate buffer. Next, we embedded the optic nerve segments in Epon resin and obtained semi-thin (700 nm, light microscopy) and ultra-thin (70 nm, electron microscopy) cross-sections. We stained semi-thin cross-sections with $1 \%$ paraphenylenediamine (PPD; in a 1:1 mixture of methanol and 2-propanol) and $1 \%$ toluidine blue to identify myelin sheaths and glia, 
respectively. We imaged sections en montage using a Nikon H600L microscope equipped with a $100 \times$ oil-immersion objective, motorized X-Y-Z stage, a digital SLR camera, and differential interference contrast optics. Ultra-thin nerve cross-sections were prepared and photographed at $2700 \times$ (10 images per nerve for axon counts) and $240 \times$ magnification (one image per nerve to measure cross-sectional nerve area) using a Philips CM-12, 120-keV transmission electron microscope at Vanderbilt Cell Imaging Shared Resource Core. A naïve observer manually counted total and degenerating axons using Fiji ImageJ. We identified degenerating axons based on multilaminar myelin sheaths and diminishment of cytoskeletal content.

\section{Behavioral Spatial Frequency Threshold Measurement}

We measured spatial frequency threshold (i.e., spatial acuity) using the OptoMotry system (Cerebral Mechanics Inc., Canada) as previously described [27, 29]. We determined spatial acuity by assessing the oculomotor reflex to drifting spatial frequency gratings at $100 \%$ contrast. Each spatial frequency was presented until a response (tracking) or no response (no tracking) was indicated by naïve experimenters. Mice were tested 3 times prior to microbead injection (baseline) and 2 times per week for 1 month after injections.

\section{Statistical Analysis}

We analyzed data using GraphPad (Version 9, GraphPad Software Inc, San Diego, CA) or SigmaPlot (Version 12, Systat Software Inc., San Jose, CA). We determined if data fit a normal distribution using Shapiro-Wilk tests. If data passed normality tests, we performed parametric statistics; otherwise, non-parametric statistics were performed. We identify each statistical test performed in figure captions in the "Results" section.

\section{Results}

\section{Bax $^{-/-}$Abates RGC Dendritic Loss During Glaucoma}

We verified the genotype of each Bax animal by gel electrophoresis of PCR products. Mice homozygous for the mutant $B a x^{\mathrm{tm} 1 \mathrm{Sjk}}$ allele $\left(B a x^{--}\right)$showed a single band at $507 \mathrm{bp}$. Heterozygous mice for the mutant $B a x^{\mathrm{tm} 1 \mathrm{Sjk}}$ allele $\left(\mathrm{Bax}^{+/-}\right)$ produced bands at $507 \mathrm{bp}$ and 307, indicating the WT Bax allele. WT animals produced only a single band at $307 \mathrm{bp}$ (Fig. 1A).

Before elevating intraocular pressure (IOP) by blocking the outflow of aqueous fluid by microbead occlusion of the trabecular meshwork, we measured IOP for 2 consecutive days (i.e., baseline). We did not detect a significant difference in baseline IOP between WT $(14.64 \pm 0.13 \mathrm{mmHg})$ and $\operatorname{Bax}^{-/-}$naïve eyes $(14.35 \pm 0.16 \mathrm{mmHg}, p=0.16$, Fig. $1 \mathrm{~B})$. Following a single injection of microbeads into the anterior chamber of the eye, we achieved a sustained increase in IOP over the duration of the experiment (1 month) for both WT $(+32.6 \%, 19.64 \pm 1.82$ vs. $14.81 \pm 1.54 \mathrm{mmHg}, p<0.001)$ and $\mathrm{Bax}^{-/-}$eyes $(+33.3 \%, 18.97 \pm 1.88$ vs. $14.23 \pm 1.36$ $\mathrm{mmHg}, p<0.001)$ compared to respective saline-injected eyes (Fig. 1B, C).

We recently reported elevating IOP for 1 month does not significantly affect the density of RBPMS-positive RGCs in WT retinas [22]. Again, we found IOP elevation does not significantly affect the density of Brn3a- (3242 \pm 167 vs. $3046 \pm 101$ cells $\left./ \mathrm{mm}^{2}, p=0.92\right)$ or SMI-32-positive RGCs in WT retinas $\left(413 \pm 22\right.$ vs. $448 \pm 5$ cells $/ \mathrm{mm}^{2}, p>0.99$, Fig. 1D-F). As previously observed [33], Bax ${ }^{-/-}$retinas contain significantly more RGCs. Similarly, we found $\mathrm{Bax}^{-}$ ${ }^{1-}$ significantly increases both Brn3a- $(+56 \%, p=0.0002)$ and SMI-32-positive RGCs $(+118 \%, p=0.01)$ compared to WTs (Fig. 1D-F). However, IOP elevation does not significantly impact either Brn3a- $\left(5066 \pm 199\right.$ vs. $4863 \pm 197$ cells $/ \mathrm{mm}^{2}$, $p=0.839$ ) or SMI-32-positive RGC density in $\mathrm{Bax}^{-/}$retinas $\left(902 \pm 58\right.$ vs. $789 \pm 188$ cells $/ \mathrm{mm}^{2}, p>0.99$, Fig. 1D-F). Collectively, our results indicate modest IOP elevation for 1 month does not significantly affect RGC density in either WT or $\mathrm{Bax}^{-1-}$ retinas.

Although we find elevating IOP for 1 month does not cause significant RGC dropout, our result does not preclude the pro-degenerative impact of IOP elevation on RGC morphology and physiology. Our laboratory and others have found that RGC dendrites and voltage-gated responses are particularly sensitive to IOP elevation [22, 34-36]. Next, we determined if Bax contributes to the phenotypic dendritic pruning and response degradation observed in WT RGCs during IOP elevation.

We identified $\alpha \mathrm{ON}$-Sustained ( $\alpha \mathrm{ON}-\mathrm{S}$ ) RGCs in WT and $\mathrm{Bax}^{-/-}$retinas. WT (Fig. 2A) and $\mathrm{Bax}^{-/-}$(Fig. 2B) $\alpha \mathrm{ON}-\mathrm{S}$ RGCs have large somas with heavy immunolabeling for SMI-32 and their dendrites terminate within the "ON" sublayer of the inner plexiform layer (IPL). $\mathrm{Bax}^{-/-}$intrinsically reduced soma area ( $p=0.02$, Fig. 2 C), SMI- 32 immunoreactivity ( $p=0.0006$, Fig. 2D), and dendritic complexity (Sholl analysis: $p \leq 0.03$; branch points: $p<0.001$, Fig. $2 \mathrm{~F}, \mathrm{G}$ ) of $\alpha \mathrm{ON}-\mathrm{S}$ RGCs compared to WTs. However, $\mathrm{Bax}^{-/-}$does not inherently alter relative dendritic depth (Fig. 2E) or dendritic field area (Fig. 2H).

After 1 month of IOP elevation, we found a significant reduction in the number of dendritic intersections (Sholl analysis, $p \leq 0.04$, Fig. $2 \mathrm{~F}$ ) and a significant, $32 \%$, decrease in branch points $(48 \pm 2$ vs. $32.7 \pm 1.4$ branch points, $p<0.001$, Fig. $2 \mathrm{G}$ ) in WT $\alpha \mathrm{ON}-\mathrm{S}$ RGCs. We confirmed this reduction in dendritic branching was not due to sampling 

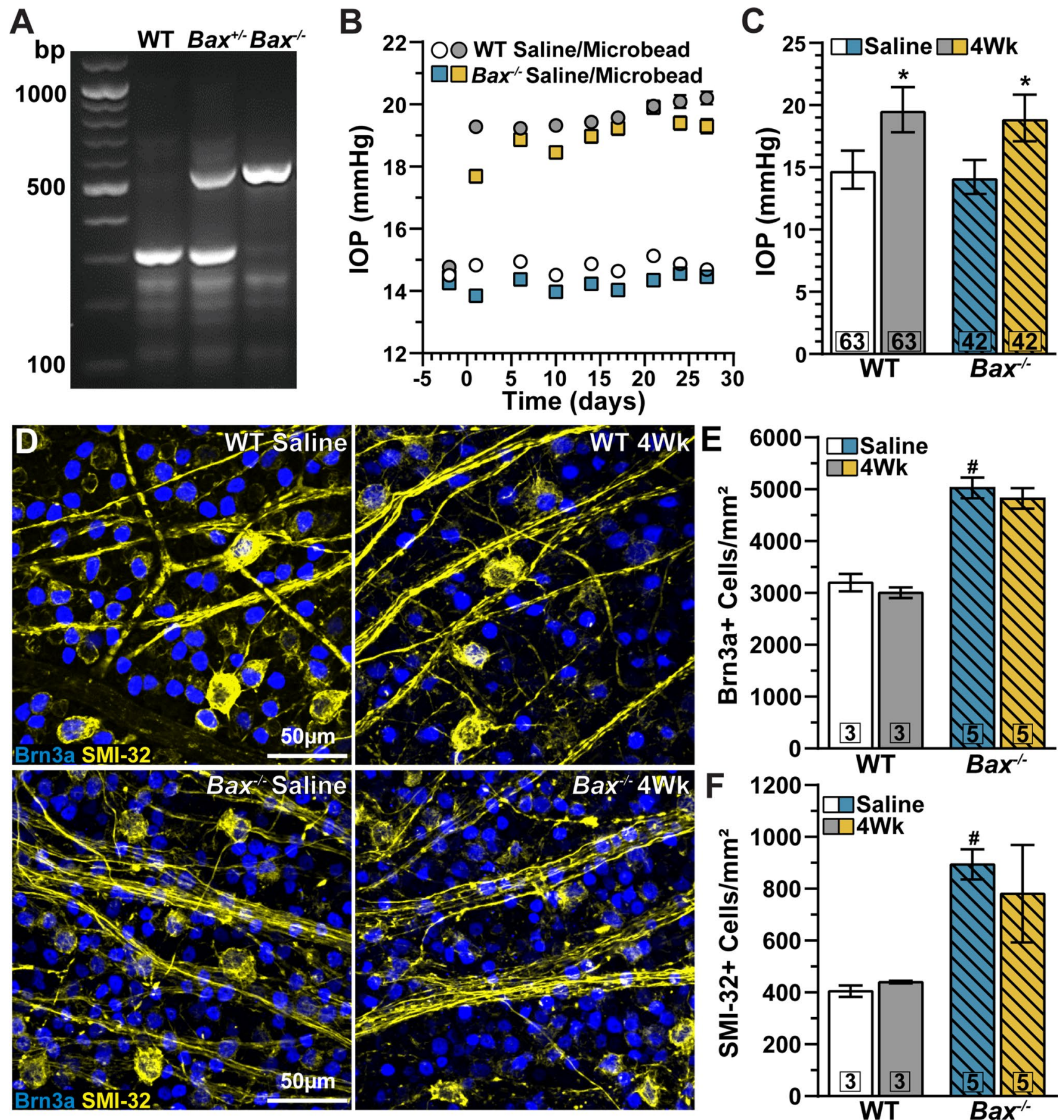

Fig. 1 Genotype confirmation, IOP elevation, and RGC density. (A) PCR products of WT (304 bp), Bax heterozygote (Bax ${ }^{+/}$; 304 bp and 507 bp) and Bax mutant (Bax ${ }^{-1-} ; 507$ bp) mice. (B) Mean intraocular pressure (IOP) of WT (circles) and $\mathrm{Bax}^{-/-}$(squares) mice before (day 0 ) and following (days $\geq 1$ ) a single unilateral injection of polystyrene microbeadsor equivalent volume of saline. (C) Microbead injection significantly elevated IOP for 4 weeks in both WT and Bax $^{-/}$mice: WT: $19.64 \pm 1.82$ vs. $14.81 \pm 1.54 \mathrm{mmHg}, p<0.001$; Bax-/-: $18.97 \pm 1.88$ vs. $14.23 \pm 1.36 \mathrm{mmHg}, p<0.001$ ). (D) Con- focal micrographs of whole-mount retinas from saline- and microbead-injected eyes of WT (top) and $\mathrm{Bax}^{-/-}$(bottom) mice immunolabeled against Brn3a (blue) and SMI-32 (yellow). (E-F) Brn3a+ and SMI-32+cell density was unaffected by 1 month of IOP elevation in both WT $(\mathrm{p} \geq 0.92)$ and $\mathrm{Bax}^{-/-}$retinas $(\mathrm{p} \geq 0.83)$. Bax $^{-/-}$retinas contain significantly more Brn3a+ and SMI-32+ cells compared to WT (\#, $p \leq 0.01)$. Statistics: Student's $t$-tests $(\mathrm{C})$, one-way ANOVA, Tukey post hoc (E), Kruskal-Wallis test, Dunn's post hoc (F). Data presented as mean \pm SEM. 


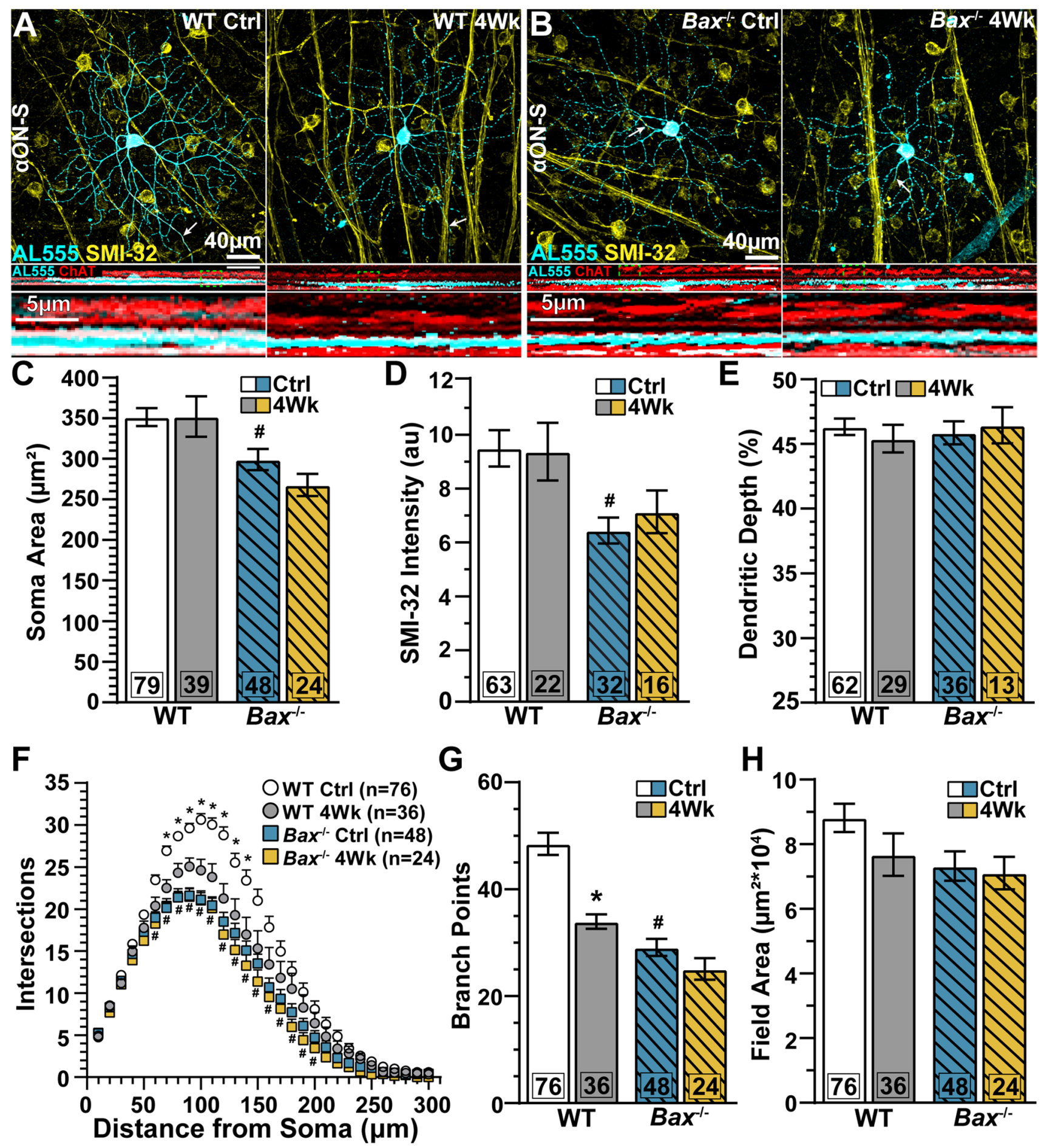

bias across retinal eccentricities by measuring the distance from the optic nerve head and comparing dendritic branching versus eccentricity. Typically, we recovered WT $\alpha \mathrm{ON}-\mathrm{S}$ RGCs from the mid peripheral retina (WT Ctrl: 1485 \pm 59 $\mu \mathrm{m}$, WT $4 \mathrm{Wk}: 1443 \pm 92 \mu \mathrm{m}$ from the optic nerve head, $p=0.98$, Fig. S1A). Similar to an earlier report [37], we did not detect a significant linear relationship between branch points and retinal eccentricity for $\mathrm{WT} \alpha \mathrm{ON}-\mathrm{S}$ from control
$\left(R^{2}=0.002, p=0.71\right)$ or microbead-injected eyes $\left(R^{2}=0.07\right.$, $p=0.21$, Fig. S1B).

$\mathrm{Bax}^{-/-}$increases retinal area [38]. Consequently, during whole-cell recording and dye-filling, we often targeted RGCs that were more distant from the optic nerve head than WT RGCs and even beyond the extent of WT retinas ( $p=0.005$, Fig. S1A). Following 1 month of IOP elevation, $\mathrm{Bax}^{-/-} \alpha \mathrm{ON}-\mathrm{S}$ RGC dendritic arbors remained intact based on 
4Fig. $2 \mathrm{Bax}^{-/-}$reduces dendritic degeneration in $\alpha \mathrm{ON}-\mathrm{S}$ RGCs during IOP elevation. (A-B) Confocal micrographs of $\alpha \mathrm{ON}$-Sustained $(\alpha \mathrm{ON}-\mathrm{S}) \mathrm{RGCs}$ filled with ALEXA 555 (AL555, cyan) from salineand microbead-injected eyes of (A) WT and (B) Bax ${ }^{-/-}$animals. $\alpha \mathrm{ON}-\mathrm{S}$ RGCs were neurochemically and morphologically identified by robust labeling against SMI-32 (yellow) and dendritic stratification within the ON sublamina of the inner plexiform layer (IPL), identified by ChAT (red). Arrows indicate RGC axons. Dashed green boxes indicate the RGC dendrites highlighted below. (C) IOP elevation did not affect soma size for either WT or $\mathrm{Bax}^{-{ }_{-}} \alpha \mathrm{ON}-\mathrm{S}$ RGCs $(p>0.99)$, but WT $\alpha \mathrm{ON}-\mathrm{S}$ RGC somas are intrinsically larger than $\alpha \mathrm{ON}-\mathrm{S}$ cell bodies from $\mathrm{Bax}^{-/-}$retinas (\#, $p=0.02$ ). (D) Regardless of genotype, elevating IOP did not significantly change SMI-32 immunolabeling intensity in $\alpha \mathrm{ON}-\mathrm{S}$ RGCs $(p \geq 0.13)$. Intensity of SMI-32 immunoreactivity is reduced in $\mathrm{Bax}^{-/-} \alpha \mathrm{ON}-\mathrm{S}$ RGCs (\#, $p=0.0006$ ). (E) $\alpha \mathrm{ON}-\mathrm{S}$ RGC dendritic depth was unaffected by IOP elevation or $\operatorname{Bax}^{-/-}(p \geq 0.87)$. (F) Sholl analysis revealed IOP elevation decreased $\alpha \mathrm{ON}-\mathrm{S}$ RGC dendritic complexity inWTs $(*, p \leq 0.04)$. Bax ${ }^{-/-} \alpha \mathrm{ON}-\mathrm{S}$ RGC dendritic arbors are intrinsically less complex compared to WTs (\#, $p \leq 0.03$ ). (G) IOP elevation significantly reduced the number of branch points of WT $\alpha \mathrm{ON}-\mathrm{S}$ RGCs $(*, p<0.001)$, but $\mathrm{Bax}^{-/-}$preserved $\alpha \mathrm{ON}-\mathrm{S}$ RGCs branch points during IOP elevation $(p<0.99)$. Bax ${ }^{-/-}$ $\alpha \mathrm{ON}-\mathrm{S}$ RGCs have fewer branch points compared to WT cells (\#, $p<0.001)$. (H) Neither genotype nor IOP elevation affected dendritic field area $(p \geq 0.23)$. The number of cells included in each dataset is indicated within each bar graph. The number of animals for each condition was: WT Ctrl $n=60$, WT 4 Wk $n=23$, Bax $^{-/-} \mathrm{Ctrl} n=39$, Bax $^{-/-}$ $4 \mathrm{Wk} n=18$. Statistics: Kruskal-Wallis test, Dunn's post hoc (C, G, H), one-way ANOVA, Tukey post hoc (D, E), two-way repeated measures anova, Tukey's post hoc (F). Data presented as mean \pm SEM.

the number of dendritic crossings (Sholl analysis, $p \geq 0.11$, Fig. $2 \mathrm{~F})$, the number of dendritic branch points $(p>0.99$, Fig. $2 \mathrm{G}$ ), and dendritic field area ( $p>0.99$, Fig. $2 \mathrm{H})$. Similar to fellow WT cells, we did not detect a significant relationship between branch points and eccentricity of $\alpha \mathrm{ON}-\mathrm{S}$ RGCs sampled from $\mathrm{Bax}^{-{ }^{--}}$control $\left(R^{2}=0.002, p=0.74\right)$ and microbead-injected eyes $\left(R^{2}=0.04, p=0.39\right.$, Fig. S1C). Overall, our findings indicate $\mathrm{Bax}^{-/}$attenuated the loss of $\alpha \mathrm{ON}-\mathrm{S}$ RGC dendritic complexity during IOP elevation.

In addition to morphological signatures, we identified $\alpha \mathrm{ON}-\mathrm{S}$ RGCs based on response to light. $\alpha \mathrm{ON}-\mathrm{S}$ RGCs from WT and $\mathrm{Bax}^{-/-}$control eyes typically maintained low spontaneous activity in darkness and produced a robust train of action potentials for the duration of light onset (Fig. 3A). $\mathrm{Bax}^{-/-}$rendered $\alpha \mathrm{ON}-\mathrm{S}$ RGCs less responsive to light with regard to the mean $(-28 \%, 56.7 \pm 4.9$ vs. $40.7 \pm$ 4.7 spikes $/ \mathrm{s}, p=0.36$, Fig. 3B) and peak firing rate $(-32 \%$, $87 \pm 6.2$ vs. $59 \pm 6$ spikes/s, $p=0.04$, Fig. 3C). However, $B a x^{-1-}$ does not affect $\alpha \mathrm{ON}-\mathrm{S}$ RGC resting membrane potential (RMP, $p=0.47$, Fig. 3D). Bax ${ }^{-/-}$intrinsically increased $\alpha \mathrm{ON}-\mathrm{S}$ RGC responses to depolarizing current injections $(p \leq 0.01$, Fig. 3E, F) and decreased the amount of current required to modulate firing rate above baseline spiking (rheobase) by $30 \%$ ( $p=0.05$, Fig. $3 \mathrm{G}$ ).

In agreement with previous studies [22, 27, 36], we found 1 month of IOP elevation significantly reduced light-evoked mean $(-33 \%, 56.7 \pm 4.9$ vs. $37.8 \pm 6.9$ spikes $/ \mathrm{s}, p=0.004$,
Fig. 3B) and peak firing rate of WT $\alpha \mathrm{ON}-\mathrm{S}$ RGCs $(-34.5 \%$, $87 \pm 6.2$ vs. $57 \pm 8.9$ spikes/s, $p=0.001$, Fig. 3 C). Contrary to WT cells, light responses of $\alpha \mathrm{ON}-\mathrm{S}$ RGCs from $\mathrm{Bax}^{-/-}$microbead eyes are similar to respective control cells $(p>0.99$, Fig. 3B, C). IOP elevation significantly depolarized WT $\alpha$ ON-S RGC RMP relative to control cells $(+5 \%,-61$ \pm 0.44 vs. $-58 \pm 0.98 \mathrm{mV}, p=0.003)$, but RMP of $\mathrm{Bax}^{-/-}$ $\alpha \mathrm{ON}-\mathrm{S}$ cells appear unaffected by IOP elevation $(p=0.97$, Fig. 3D). After 1 month of IOP elevation, responses of $\alpha \mathrm{ON}-\mathrm{S}$ RGCs to depolarizing current injections ( $p \geq 0.30$, Fig. 3E, F) and rheobase ( $p \geq 0.41$, Fig. 3G) are comparable to control cells independent of genotype.

Next, we identified $\alpha$ OFF-Sustained ( $\alpha \mathrm{OFF}-\mathrm{S}$ ) RGCs in both WT (Fig. 4A) and Bax ${ }^{-/-}$retinas (Fig. 4B) based on their large cell bodies, modest immunoreactivity to SMI-32, dendritic stratification just distal to the "OFF" sublamina of the IPL, and response to light $[26,27,36]$. Relative to WT control cells, $\mathrm{Bax}^{-/-}$does not drastically alter $\alpha \mathrm{OFF}-\mathrm{S}$ RGC soma area ( $p=0.16$, Fig. 4 C), SMI-32 immunolabeling ( $p>0.99$, Fig. 4D), or relative dendritic depth within the IPL ( $p>0.99$, Fig. 4E). However, $\mathrm{Bax}^{-/-}$significantly reduced the number of dendritic intersections (Sholl analysis, $p \geq 0.04$, Fig. 4F), branch points ( $p<0.001$, Fig. $4 \mathrm{G})$, and field area $(p=0.002$, Fig. $4 \mathrm{H})$ of $\alpha \mathrm{OFF}-\mathrm{S}$ RGCs from control retinas compared to WT control cells of the same type.

Following 1 month of IOP elevation, the number of dendritic branching points in WT $\alpha$ OFF-S RGCs decreased by $22 \%(55.7 \pm 2$ vs. $43.3 \pm 1.9$ branch points, $p=0.02$, Fig. 4G). However, IOP elevation did not significantly affect dendritic branch points of $\alpha \mathrm{OFF}-\mathrm{S}$ RGC from $\mathrm{Bax}^{-/-}$animals $(37.7 \pm 2.8$ vs. $36.4 \pm 3.3$ branch points, $p>0.99$, Fig. $4 \mathrm{G})$. We confirmed these findings by measuring the distance from the optic nerve head for most cells. We found $\alpha$ OFF-S RGCs from WT control $(1545 \pm 82 \mu \mathrm{m})$ and microbead-injected eyes $(1598 \pm 127 \mu \mathrm{m})$ similarly located in the mid peripheral retina ( $p=0.98$, Fig. S1D), and so too were $\alpha$ OFF-S RGCs from $\mathrm{Bax}^{-/}$control $(2168 \pm 113 \mu \mathrm{m})$ and microbead eyes $(1934 \pm 184 \mu \mathrm{m}, \mathrm{p}=0.61$, Fig. S1D). We did not detect a significant relationship between branch points and distance from optic nerve head of $\alpha$ OFF-S RGCs from WT control eyes $\left(R^{2}=0.06, p=0.09\right)$, but this relationship strengthened following IOP elevation $\left(R^{2}=0.3, p=0.01\right.$, Fig. S1E). We did not observe a significant relationship between dendritic branching and eccentricity of $\alpha \mathrm{OFF}-\mathrm{S}$ RGCs from $\mathrm{Bax}^{-/}$ control $\left(R^{2}=0.002, p=0.82\right)$ or microbead-injected eyes $\left(R^{2}=0.09, p=0.26\right.$, Fig. S1F). Based on our results, Bax appears to promote dendritic pruning of $\alpha \mathrm{OFF}-\mathrm{S}$ RGCs during IOP elevation.

In addition to morphological features, we also identified $\alpha$ OFF-S RGCs by their physiologic responses $[26,27,35$, 36]. $\alpha$ OFF-S RGCs from both WT and $\mathrm{Bax}^{-/-}$mice produced spontaneous action potentials during darkness, which were suppressed during light onset, and generated a sustained 


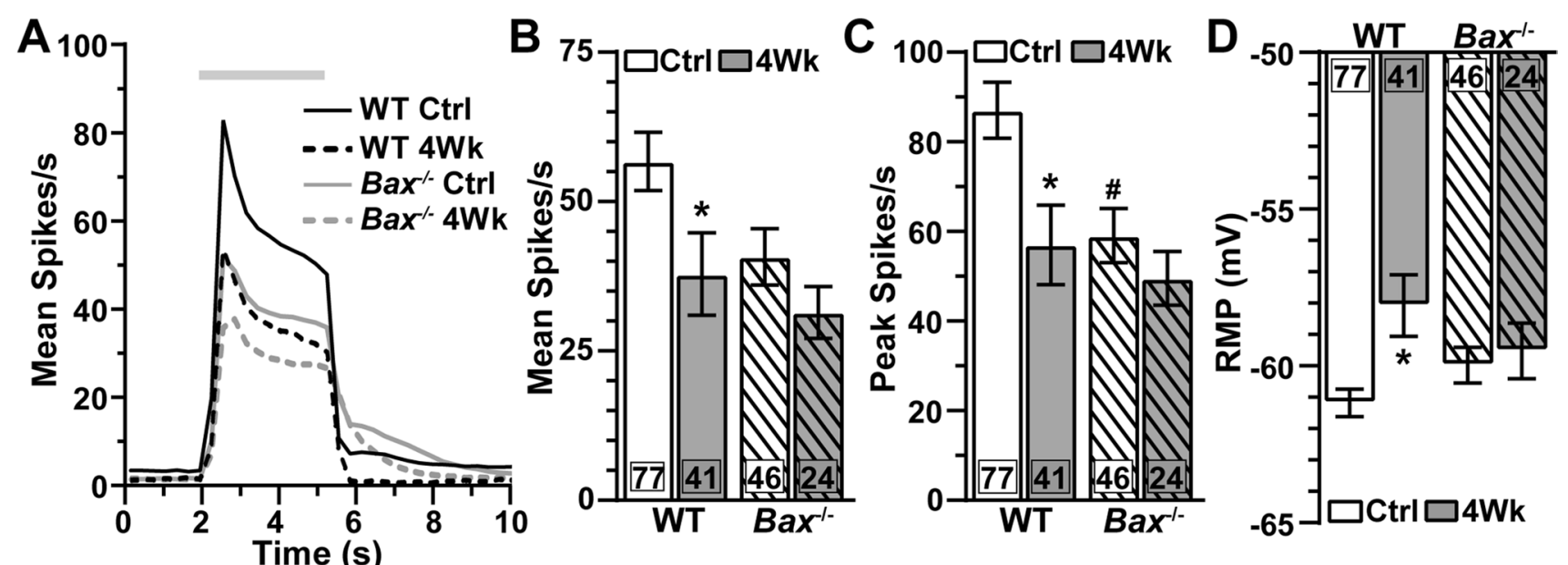

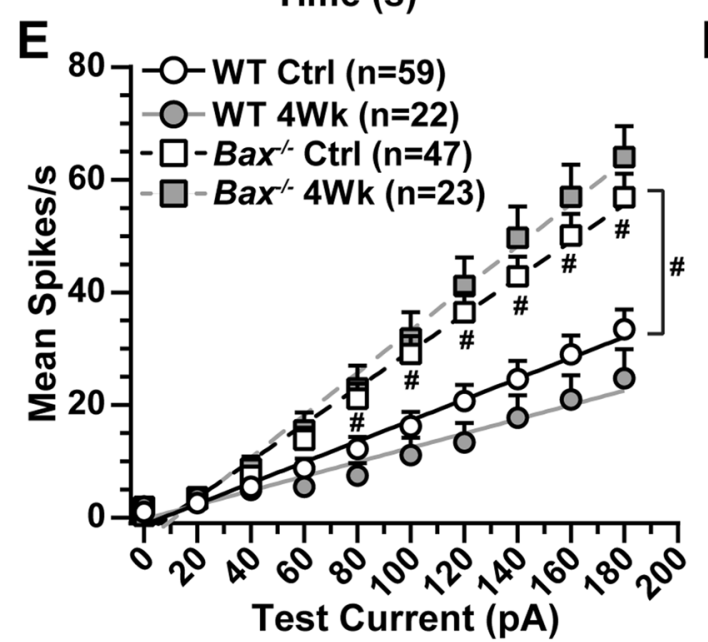

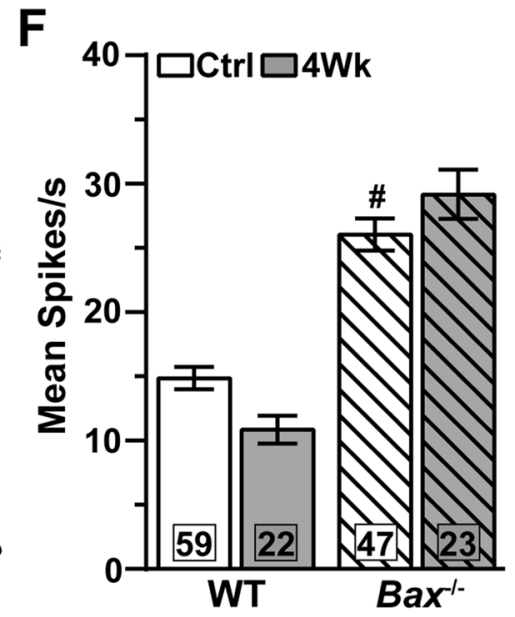

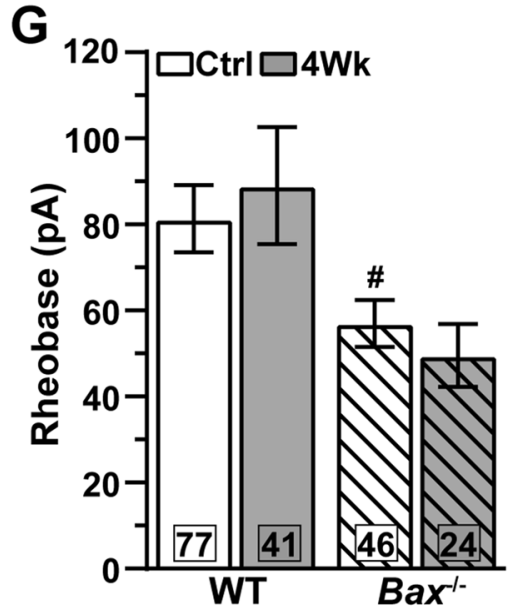

Fig. $3 \mathrm{Bax}^{-/}$protects light-evoked responses of $\alpha \mathrm{ON}-\mathrm{S}$ RGCs during IOP elevation. (A) Mean spike rate (300 ms bin width) of $\alpha \mathrm{ON}-\mathrm{S}$ RGCs from saline- and microbead-injected eyes of WT and $\mathrm{Bax}^{-/-}$mice. Light duration $(3 \mathrm{~s})$ is indicated by the light gray horizontal line. (B-C) IOP elevation significantly diminished mean and peak light-evoked spike rate of WT $\alpha \mathrm{ON}-\mathrm{S}$ RGCs (mean: *, $p=0.004$; peak: *, $p=0.001$ ), but $\mathrm{Bax}^{-/-} \alpha \mathrm{ON}-\mathrm{S}$ RGC light responses remained intact $(p<0.99)$. Bax ${ }^{-/-}$decreased light-evoked peak firing rate of $\alpha \mathrm{ON}-\mathrm{S}$ RGCs compared to WT cells $(\#, p=0.04$ ). (D) IOP elevation significantly depolarized resting membrane potential (RMP) of WT $\alpha$ ON-S RGCs (*, $p=0.003$ ) but did not influence RMP in Bax /. $\alpha \mathrm{ON}-\mathrm{S}$ RGCs $(p=0.97)$. (E) Average spike rate of $\alpha \mathrm{ON}-\mathrm{S}$ RGCs from saline- and microbead-injected eyes of WT and $\mathrm{Bax}^{-/-}$mice to a series of depolarizing current injections ( 0 to $180 \mathrm{pA}$ in $20 \mathrm{pA}$ increments). IOP elevation did not significantly alter current-induced spike rate for either WT $(p \geq 0.37)$ or Bax $^{-/-}(p \geq 0.30) \alpha \mathrm{ON}-\mathrm{S}$ RGCs. Bax ${ }^{-/-}$

burst of action potentials after light offset (Fig. 5A). $\alpha$ OFF-S $\mathrm{RGC}$ light responses from $\mathrm{Bax}^{-/-}$control eyes were generally smaller than their WT counterparts (Mean Spike Rate: 28.36 \pm 2.65 vs. $20.48 \pm 2$ spikes/s, $p=0.52$; Peak Spike Rate: 52.1 \pm 4.4 vs. $32.4 \pm 2.8$ spikes/s, $p=0.007$, Fig. $5 \mathrm{~B}, \mathrm{C}) . \mathrm{Bax}^{-}$ ${ }^{1-}$ did not significantly affect RMP of $\alpha \mathrm{OFF}-\mathrm{S}$ RGCs from control eyes ( $p>0.99$, Fig. 5D). Contrary to light responses, when we stimulated WT and $\mathrm{Bax}^{-{ }_{-}-}$control $\alpha \mathrm{OFF}-\mathrm{S}$ RGCs with depolarizing current injections, we found mean spike increased $\alpha \mathrm{ON}-\mathrm{S}$ RGCs from control retinas current-evoked spiking compared to WT cells from control retinas $(\#, p \leq 0.01)$. Lines indicate best-fit linear regressions: WT Ctrl $R^{2}=0.25$, WT $4 \mathrm{Wk} \mathrm{R}{ }^{2}=0.21$, Bax $^{-/-}$Ctrl $R^{2}=0.47$, Bax $^{-/-} 4 \mathrm{Wk} R^{2}=0.55$. The rate of change (slope) between spike rate and test current significantly increased for Bax $^{-}$ I- control $\alpha \mathrm{ON}-\mathrm{S}$ RGCs compared to WTs $(\#, p=0.0002)$. (F) Bax ${ }^{-1-}$ significantly increased spike activity averaged across current pulses (\#, $p<0.001$ ). (G) One month of elevated IOP did not significantly affect WT or $\mathrm{Bax}^{-/-} \alpha \mathrm{ON}-\mathrm{S}$ rheobase $(p \geq 0.41)$, but $\mathrm{Bax}^{-/-}$intrinsically reduces rheobase (\#, $p=0.05)$. The number of cells included in each dataset is indicated within each bar graph. The number of animals for each condition was: WT $\operatorname{Ctrl} n=57$, WT $4 \mathrm{Wk} n=24, \operatorname{Bax}^{-/-} \mathrm{Ctrl} n=39$, $\mathrm{Bax}^{-/-}$4Wk $n=18$. Statistics: Kruskal-Wallis test, Dunn's post hoc (B, $\mathrm{C}, \mathrm{F}, \mathrm{G})$, one-way ANOVA, Tukey post hoc (D), two-way repeated measures ANOVA (E). Data presented as mean \pm SEM.

rate ( $p \geq 0.17$, Fig. 5E, F) and rheobase ( $p=0.12$, Fig. 5G) to be similar.

One month of IOP elevation reduced the mean (28.4 \pm 2.65 vs. $19.7 \pm 3.56$ spikes/s, $p=0.13$, Fig. 5 B) and peak firing rate at light offset of WT $\alpha \mathrm{OFF}-\mathrm{S}$ RGCs $(52.1 \pm 4.4$ vs. $35.3 \pm 6$ spikes/s, $p=0.05$, Fig. $5 \mathrm{C})$. Bax $^{-/-}$prevented this IOP-induced reduction in light-evoked mean $(p=0.91)$ and peak spike rate $(p=0.73)$ in $\alpha$ OFF-S RGCs (Fig. 5B, C). $\mathrm{Bax}^{-/-}$does not appear to protect firing rate through 
mechanisms generating RMP because RMP of $\alpha \mathrm{OFF}-\mathrm{S}$ from control and microbead eyes is similar independent of genotype ( $p=0.12$, Fig. 5D).

Next, we tested the impact of IOP elevation on $\alpha \mathrm{OFF}-\mathrm{S}$ RGC responses to a series of depolarizing current injections. Like the reduction in light responses, 1 month of IOP elevation decreased spike rate at suprathreshold test currents in WT $\alpha$ OFF-S RGCs ( $p \geq 0.03$, Fig. 3E), and significantly reduced the average spike rate to depolarizing currents $(p=0.001$, Fig. 5F). However, IOP elevation does not significantly affect $\mathrm{Bax}^{-/-} \alpha \mathrm{OFF}-\mathrm{S}$ RGC responses to depolarizing currents ( $p \geq 0.11$, Fig. 5E, F) or rheobase ( $p>0.99$, Fig. 5G). Taken together, our results show IOP elevation significantly alters WT RGC morphology and physiology regardless of cell type, and this pathology is largely undetectable in the absence of Bax.

\section{Axonopathy Endures in Bax ${ }^{-/-}$Mice}

Degradation of RGC anterograde axon transport to the superior colliculus (SC) is an early indicator of axonopathy in glaucoma [31, 39]. Anterograde axon transport deficits occur prior to optic nerve axon degeneration and loss of postsynaptic target neurons of the SC [31, 39]. Based on this premise, we investigated anterograde axon transport of cholera toxin subunit B (CTB-488) to the SC. Following 1 month of IOP elevation, we observed a reduction in intact anterograde transport of CTB-488 to the SC in both WT and $\mathrm{Bax}^{-1-}$ mice (Fig. 6A). When quantified, we found IOP elevation significantly diminished the percent of intact transport in WT $(-35 \%, p=0.0002)$ and Bax $^{-/-}$mice $(-21 \%, \mathrm{p}=0.03$, Fig. 6B). We did not observe a statistical difference in the percentage of intact transport in the SC of WT and $\mathrm{Bax}^{-1-}$ mice subjected to IOP elevation ( $p=0.95$, Fig. $6 \mathrm{~B})$.

The IOP-induced loss of anterograde axon transport to the SC does not appear to be due to outright degeneration of RGC axons in the optic nerve proper or SC neurons. As noted by others, and confirmed here, $\mathrm{Bax}^{-/-}$intrinsically increased optic nerve size and axon density (Fig. S2A, B). When quantified, we found $\mathrm{Bax}^{-/-}$significantly increased optic nerve cross-sectional area by $59 \%$ (60420 \pm 4975 vs. $96308 \pm 11607 \mu \mathrm{m}^{2}, p=0.009$, Fig. S2E). As a corollary, $\mathrm{Bax}^{-/-}$also significantly increased optic nerve axon density $\left(+56 \%, 0.55 \pm 0.05\right.$ vs. $0.87 \pm 0.02$ axons $/ \mu \mathrm{m}^{2}, p=0.0005$, Fig. S2F). We observed no significant difference in the percent of degenerating axons between WT $(2.94 \%)$ and $\mathrm{Bax}^{-/-}$ $(2.12 \%)$ optic nerves from control eyes ( $p=0.85$, Fig. S2G). Following 1 month of IOP elevation, we found optic nerve cross-sectional area $(p \geq 0.98)$, axon density ( $p \geq 0.17)$, and the percentage of degenerating axons $(p \geq 0.76)$ largely unchanged in both WT and $\mathrm{Bax}^{-/-}$mice (Fig. S2E-G). The increase in RGC axon density observed in $\mathrm{Bax}^{-/-}$optic nerves is supported by a modest increase in SC neuron density
( $p=0.09$, Fig. 6C), but we did not detect a significant effect of IOP elevation on NeuN-positive cell density in the SC of either WT or Bax ${ }^{-/-}$animals ( $p \geq 0.82$, Fig. 6C).

We recently reported 1 month of IOP elevation worsens spatial frequency threshold (spatial acuity) in WT mice [22]. Here, we determined the influence of Bax on spatial acuity when challenged by IOP elevation. We measured the optomotor response to a series of $100 \%$ contrast sinusoidal gratings varying by spatial frequency. We found spatial acuity is similarly reduced for both WT and $\mathrm{Bax}^{-1-}$ mice over the course of IOP elevation $(p>0.99$, Fig. 6D).

Interestingly, $\mathrm{Bax}^{-1-}$ intrinsically improved spatial acuity by $21 \%$ compared to WT control eyes $(0.52 \pm 0.025$ vs. $0.63 \pm 0.016 \mathrm{c} / \mathrm{d}, p<0.001$, Fig. $6 \mathrm{E})$. Moreover, we found spatial acuity of $\mathrm{Bax}^{-1-}$ microbead-injected eyes is modestly better than microbead-injected eyes of WT mice $(+24.8 \%$, $p=0.05)$ and not significantly different compared to salineinjected eyes of WTs ( $p=0.73$, Fig. $6 \mathrm{E})$. Following 1 month of IOP elevation, spatial acuity significantly decreased in the microbead-injected eyes of both WT $(-25.5 \%, p=0.0009)$ and $\mathrm{Bax}^{-/-}(-23.8 \%, p=0.004)$ animals compared to respective control eyes (Fig. 6E).

\section{Discussion}

Our results confirm and extend the evidence that $\mathrm{Bax}^{-/-}$profoundly effects RGC somato-dendritic and axonal morphology [33, 40]. Bax deficiency increases RGC density (Fig. 1D-F), decreases RGC soma size and dendritic arbor complexity (Fig. 2C, F, G; Fig. 4C, F, G), and increases optic nerve area and RGC axon density (Fig. S2). Despite these gross morphological changes, alpha-type RGCs retain some semblance of their molecular (Figs. 1D, 2D, and 4D), morphological (Figs. 2E and 4E), and physiologic identity (Fig. 3A-D; Fig. 5A-D).

We found 1 month of IOP elevation does not cause significant RGC body degeneration in either WT or $\mathrm{Bax}^{-/-}$retinas (Fig. 1D-F). Similarly, we have previously found IOP elevation by microbead occlusion of the trabecular meshwork for 1 month does not cause significant RGC body dropout $[22,41]$. Although 1 month of IOP elevation does not produce significant RGC body elimination [22, 41], RGC dendritic arbor complexity diminishes in the presence of $\mathrm{Bax}$ $[22,27,36]$. Here, we found this to be true for both $\alpha \mathrm{ON}-\mathrm{S}$ (Fig. 2G) and $\alpha$ OFF-S RGCs from WT retinas (Fig. $4 \mathrm{G}$ ). $\mathrm{Bax}^{-/-}$reduces dendritic pruning of $\alpha \mathrm{RGCs}$ during IOP elevation (Figs. $2 \mathrm{G}$ and $4 \mathrm{G}$ ).

How does $\mathrm{Bax}^{-/-}$protect RGC dendrites against IOPinduced degeneration? In the absence of Bax, RGCs may be less vulnerable to injury because cells are inherently smaller and less complex (Figs. 2 and 4). Previously, we have found 

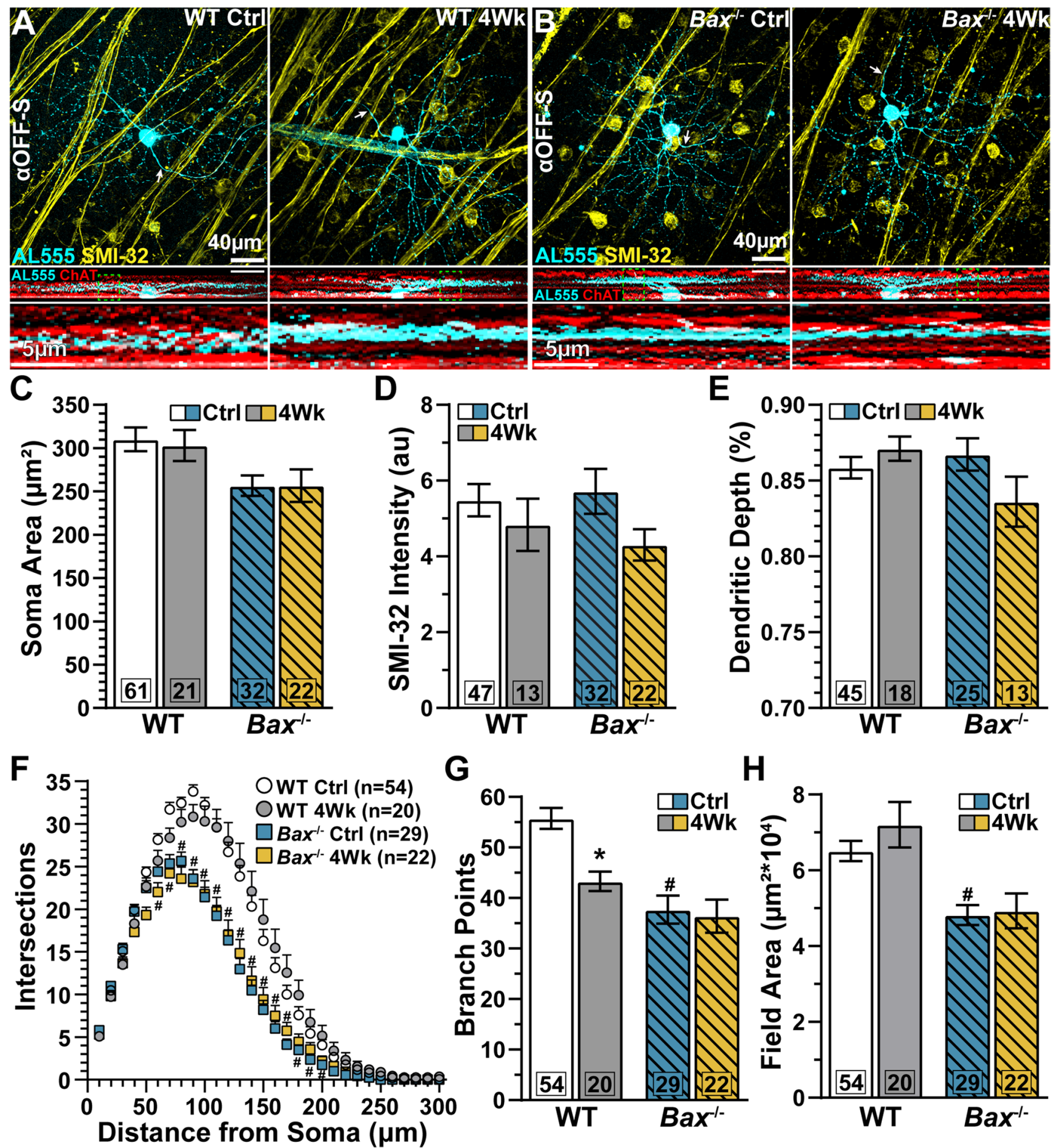

evidence lending support to this idea. Mutation in the transient receptor potential vanilloid 1 (TRPV1) channel, which signal stress through calcium conductance, also intrinsically reduces $\alpha \mathrm{RGC}$ dendritic complexity, and the dendrites of these very cells are less vulnerable to degeneration during IOP elevation [26]. However, the possibly also exists that in the absence of stress-induced TRPV1-mediated calcium signaling, dendrites are less susceptible to degeneration.
To overcome this problem of determining the influence of intrinsic developmental versus mechanistic changes on outcome measurements, which is typical when using conventional genetic models, inducible genetic constructs may be employed [42].

An alternative and mechanistic hypothesis for dendritic degeneration in WT RGCs is BAX also serves non-apoptotic functions that contribute to dendritic pruning [23, 
४Fig. $4 \mathrm{Bax}^{-1-}$ protects $\alpha$ OFF-S RGC dendrites during IOP elevation. (A-B) Representative $\alpha$ OFF-S RGCs from whole-mount retinas of saline- and microbead-injected eyes of (A) WT and (B) $\mathrm{Bax}^{-/-}$mice. RGCs were filled with ALEXA 555 (AL555, cyan) and morphologies were recovered by confocal microscopy. $\alpha \mathrm{OFF}-\mathrm{S}$ RGCs were neurochemically identified by modest immunoreactivity for SMI32 (yellow) and morphologically characterized by dendritic arbor stratification within the distal OFF sublamina of the IPL defined by immunolabeling against ChAT (red). RGC axons indicated by arrows. Dashed green boxes show the dendritic ramifications highlighted below. (C-E) Neither IOP elevation nor $\mathrm{Bax}^{-/-}$significantly impacted $\alpha$ OFF-S RGC (C) soma area ( $p \geq 0.13)$, (D) SMI-32 immunolabeling ( $p \geq 0.74)$, or (E) dendritic depth ( $p \geq 0.34)$. (F) Sholl analysis of WT and $\mathrm{Bax}^{-/-} \alpha \mathrm{OFF}-\mathrm{S}$ dendritic intersections from saline- and microbead-injected eyes. IOP elevation did not significantly influence the number of dendritic crossings in WT $(p \geq 0.09)$ or Bax $^{-/-} \alpha \mathrm{OFF}-\mathrm{S}$ RGCs $(p \geq 0.07)$. $\mathrm{Bax}^{-/-} \alpha \mathrm{OFF}-\mathrm{S}$ RGCs have fewer dendritic crossings compared to WTs (\#, $p \leq 0.04)$. (G) Elevating IOP significantly diminished the number of dendritic branch points of WT $\alpha \mathrm{OFF}-\mathrm{S}$ $(*, p=0.02) . \mathrm{Bax}^{-/}$protects $\alpha \mathrm{OFF}-\mathrm{S}$ dendritic branch points during IOP elevation $(p>0.99)$. The number of $\alpha$ OFF-S dendritic branch points is significantly reduced by $\mathrm{Bax}^{-/}$compared to WT controls $(\#, p<0.001)$. (H) Elevating IOP did not affect dendritic field area of $\alpha$ OFF-S RGCs of WT or Bax $x^{-1-}$ mice $(p \geq 0.55)$. Bax ${ }^{-1-}$ significantly reduced $\alpha$ OFF-S RGC dendritic field area compared to WT controls (\#, $p=0.002$ ). The number of cells included in each dataset is indicated within each bar graph. The number of animals for each condition was: WT Ctrl $n=43$, WT $4 \mathrm{Wk} n=18$, Bax $^{-/-} \mathrm{Ctrl} n=27$, Bax $^{-{ }^{-}}$ 4Wk $n=16$. Statistics: Kruskal-Wallis test, Dunn's post hoc (C, D, E, G), two-way repeated measures ANOVA, Tukey's post hoc (F), oneway ANOVA, Tukey post hoc $(\mathrm{H})$. Data presented as mean \pm SEM.

43-46]. Local short-term activation of BAX/caspase-3 causes loss of excitatory surface receptors and dendritic pruning in the absence of apoptosis [42, 43, 47, 48]. Like the non-apoptotic actions of BAX, the complement pathway contributes to sculpting dendritic arbors and synapses following injury [13, 42, 43, 49, 50]. During DBA2/J glaucoma, complement protein C1qa increasingly colocalizes to PSD-95 within RGC dendrites, marking synapses for elimination [50]. Genetic deletion of Clqa or pharmacological antagonism of complement component, $\mathrm{C} 1$, reduces dendritic degeneration during glaucoma [13]. Taken together, upregulation of $\mathrm{C} 1 \mathrm{q}$ might promote the activation of BAX during stress, leading to dendritic pruning in RGCs [51].

$\mathrm{Bax}^{-/-}$also appears to protect light- and current-evoked responses of $\alpha \mathrm{ON}-\mathrm{S}$ and $\alpha \mathrm{OFF}-\mathrm{S}$ RGCs during IOP elevation (Figs. 3 and 5). As we have previously reported [22, 27], and confirm here, 1 month of IOP elevation significantly reduced light-evoked responses of WT $\alpha \mathrm{ON}-\mathrm{S}$ (Fig. 3A-C) and $\alpha$ OFF-S RGCs (Fig. 5A-C). Similarly, IOP elevation modestly reduced responses of $\alpha \mathrm{ON}-\mathrm{S}$ RGCs to current stimulation (Fig. 3E, F) and significantly diminished currentevoked responses of $\alpha \mathrm{OFF}-\mathrm{S}$ RGCs (Fig. 5E, F). However, we found light- and current-evoked responses of $\alpha \mathrm{ON}-\mathrm{S}$ (Fig. 3E, F) and $\alpha$ OFF-S RGCs (Fig. 5E, F) from $\mathrm{Bax}^{-/-}$retinas resistant to degradation caused by IOP elevation.
Bax appears to contribute to the IOP-induced reduction in light- and current-evoked responses of WT RGCs (Figs. 3 and 5). This claim is supported by evidence showing that modest activation of $\mathrm{BAX} /$ caspase- 3 is required for the induction of NMDA receptor-mediated long-term depression (LTD) through the endocytosis of AMPA receptors [42]. As a corollary, Bax knockdown inhibits induction of LTD [42]. Interestingly, not only do we find $\mathrm{Bax}^{-/-}$protects light- and current-evoked responses during IOP elevation, but the current-evoked responses of $\alpha \mathrm{ON}-\mathrm{S}$ RGCs from $\mathrm{Bax}^{-/-}$control eyes are significantly larger and rheobase smaller compared to WTs (Fig. 3E-G). This enhancement in current-evoked activity of $\alpha \mathrm{ON}-\mathrm{S}$ RGCs from $\mathrm{Bax}^{-/-}$retinas may be due to a lack of LTD. Unlike WT $\alpha \mathrm{ON}-\mathrm{S}$ RGCs, current-evoked responses from $\mathrm{Bax}^{-/-} \alpha \mathrm{OFF}-\mathrm{S}$ RGCs are like those from WT retinas (Fig. 5E-G). In agreement with these divergent findings, only $\alpha \mathrm{ON}-\mathrm{S}$ RGCs utilize NMDA receptor-mediated synaptic plasticity [52]. In regard to $\alpha \mathrm{OFF}-\mathrm{S}$ RGCs, we predict responses decline during stress due to increased metabolic burden to support electrogenic mechanisms [22]. In respect to metabolism, $\mathrm{Bax}^{-/-}$may also support physiologic responses of $\alpha$ OFF-S RGCs, in particular, by protecting mitochondrial respiration and decreasing the amount of reactive oxygen species caused by nerve growth factor deprivation during stress [53-57].

As noted above, we found current-evoked responses of $\alpha \mathrm{ON}-\mathrm{S}$ and $\alpha \mathrm{OFF}-\mathrm{S}$ RGCs from $\mathrm{Bax}^{-/-}$control eyes are similar to or exceeded responses of their WT counterparts (Fig. 3E, F; Fig. 5 E, F). This finding is unsurprising given that smaller cells are typically more excitable [58]. However, the light responses of $\alpha \mathrm{ON}-\mathrm{S}$ and $\alpha \mathrm{OFF}-\mathrm{S}$ RGCs from $\mathrm{Bax}^{-}$ I- control eyes were typically smaller compared to respective cell types from WT control eyes. This result could be explained by a decrease in excitatory input. This idea is supported by our finding that $\mathrm{Bax}^{-{ }_{-}}$reduces dendritic field complexity for both $\alpha \mathrm{ON}-\mathrm{S}$ (Fig. 2F, G) and $\alpha \mathrm{OFF}-\mathrm{S}$ RGCs (Fig. 4F, G). Similarly, Bax $^{-/-}$reduces dendritic field area of VGluT3-positive amacrine and type 7 cone bipolar cells [59, 60]. Although $\mathrm{Bax}^{-/-}$decreases bipolar cell dendritic field area, the number of synapses with cone axons is similar to WT [59]. In support of these anatomical data, we find spatial acuity is naturally increased in control eyes of $\mathrm{Bax}^{-/-}$mice (Fig. 6E). These data indicate, $\mathrm{Bax}^{-/-}$increases spatial resolution at the expense of light sensitivity.

Finally, we found 1 month of IOP elevation significantly reduces anterograde axon transport (Fig. 6A, B) and spatial acuity (Fig. 6D, E) in WT and Bax ${ }^{-1-}$ mice. Axon transport and spatial acuity deficits occurred due to IOP elevation and prior to outright RGC body (Fig. 1D-F) and axon degeneration (Fig. S2). Our findings extend the evidence that axonopathy endures not only during DBA2/J glaucoma or acute injury to the optic nerve but also in induced glaucoma in the absence of $\operatorname{Bax}[14,18,23]$. The neuroprotective influence of $\mathrm{Bax}^{-/-}$on 

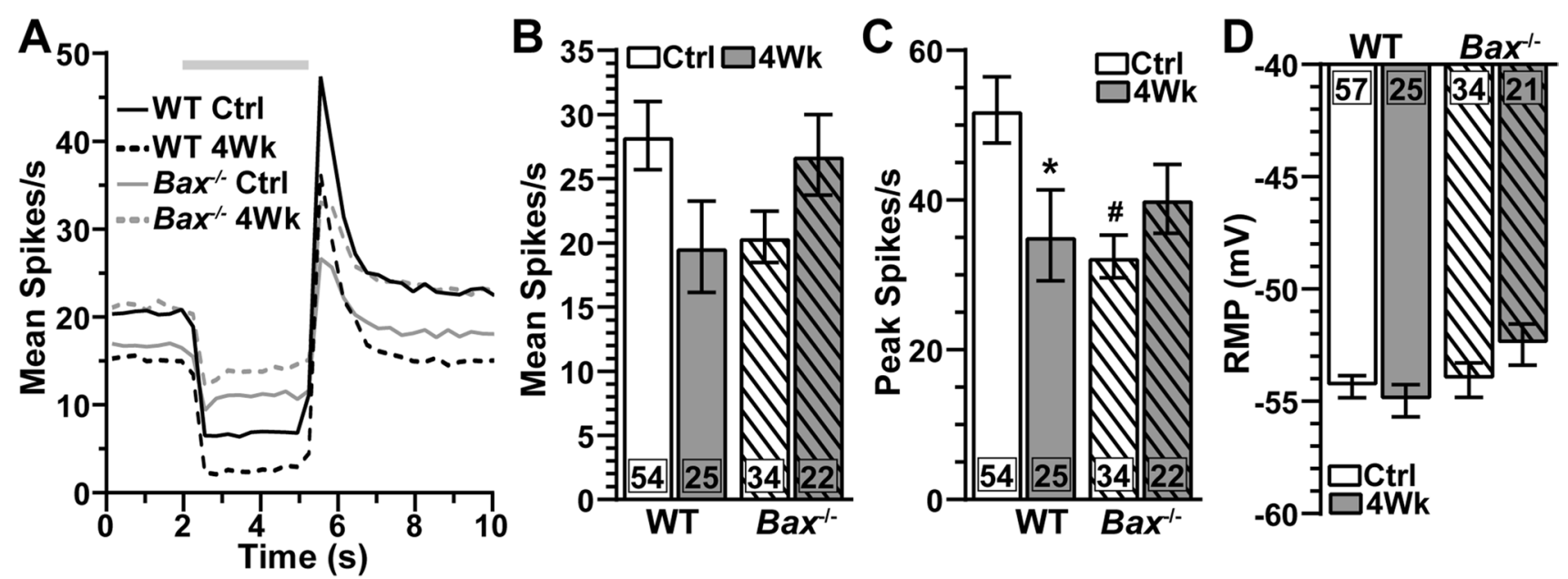

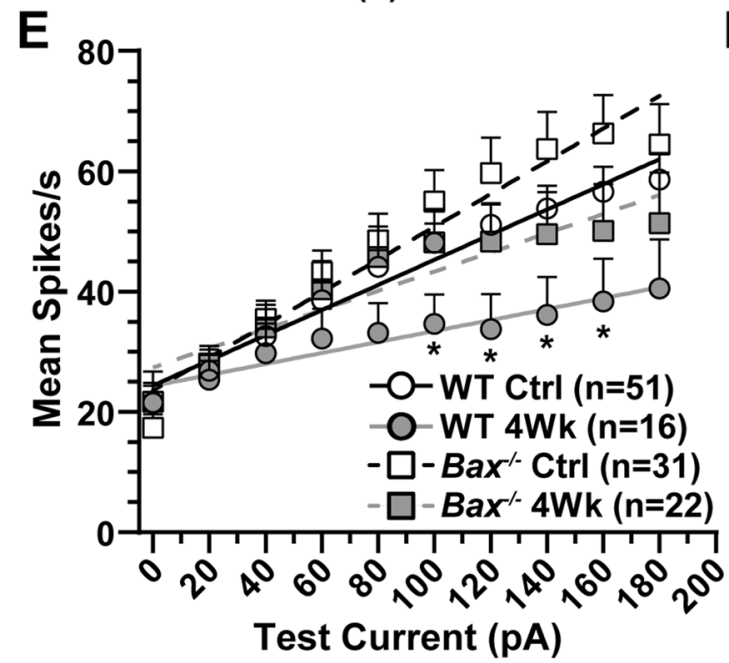

Fig. $5 \mathrm{Bax}^{-/-}$protects light- and current-evoked responses of $\alpha \mathrm{OFF}-\mathrm{S}$ RGCs during glaucoma. (A) Light-evoked spike rate histograms of $\alpha$ OFF-S RGCs from saline- and microbead-injected eyes of WT and $\mathrm{Bax}^{-/}$animals. Light duration is indicated by the horizontal light gray line. (B) IOP elevation did not significantly affect the mean lightevoked spike rate in either WT $(p=0.13)$ or $\mathrm{Bax}^{-/-} \alpha \mathrm{OFF}-\mathrm{S}$ RGCs $(p=0.90)$. (C) Elevating IOP significantly blunted the light-induced peak firing of WT $\alpha$ OFF-S RGCs $\left(^{*}, p=0.05\right.$ ), but $\mathrm{Bax}^{-/-}$protects peak spike rate in these cells $(p=0.73)$. Bax $^{-1-}$ reduced peak firing rate of $\alpha$ OFF-S RGCs (\#, $p=0.007$ ). (D) After 1 month of IOP elevation, RMP of $\alpha$ OFF-S RGCs is similar to respective control cells $(p \geq 0.43)$. (E) IOP elevation significantly reduced current-evoked spike rate of
WT $\alpha$ OFF-S RGCs $(*, p \leq 0.03)$. Lines represent best-fit linear regressions. WT Ctrl $R^{2}=0.20$, WT $4 \mathrm{Wk} R^{2}=0.05$, Bax $^{-/}$Ctrl $R^{2}=0.25$, $B a x^{-/-} 4 \mathrm{Wk} R^{2}=0.10$. (F) IOP elevation significantly decreased spike activity of WT $\alpha \mathrm{OFF}-\mathrm{S}$ RGCs when averaged across current pulses $\left(^{*}, p<0.001\right)(\mathrm{G})$ Following 4 weeks of IOP elevation, WT and $B a x^{-1-}$ $\alpha$ OFF-S RGC rheobase is similar to respective control cells $(p \geq 0.08)$. The number of cells included in each dataset is indicated within each bar graph. The number of animals for each condition was WT Ctrl $n=39$, WT 4Wk $n=19$, Bax ${ }^{-/-}$Ctrl $n=27$, Bax $^{-/-}$4Wk $n=16$. Statistics: Kruskal-Wallis test, Dunn's post hoc (B, D, F, G), one-way ANOVA, Tukey post hoc (C), two-way repeated measures ANOVA. Two-stage linear step-up post hoc (E). Data presented as mean \pm SEM.
RGC somas [14, 18, 23] and dendrites (Figs. 2 and 4) concurrent with axonopathy (Fig. 6A, B), reinforces the separability of the proximal and distal programs for neurodegeneration during glaucoma $[11,12]$. 

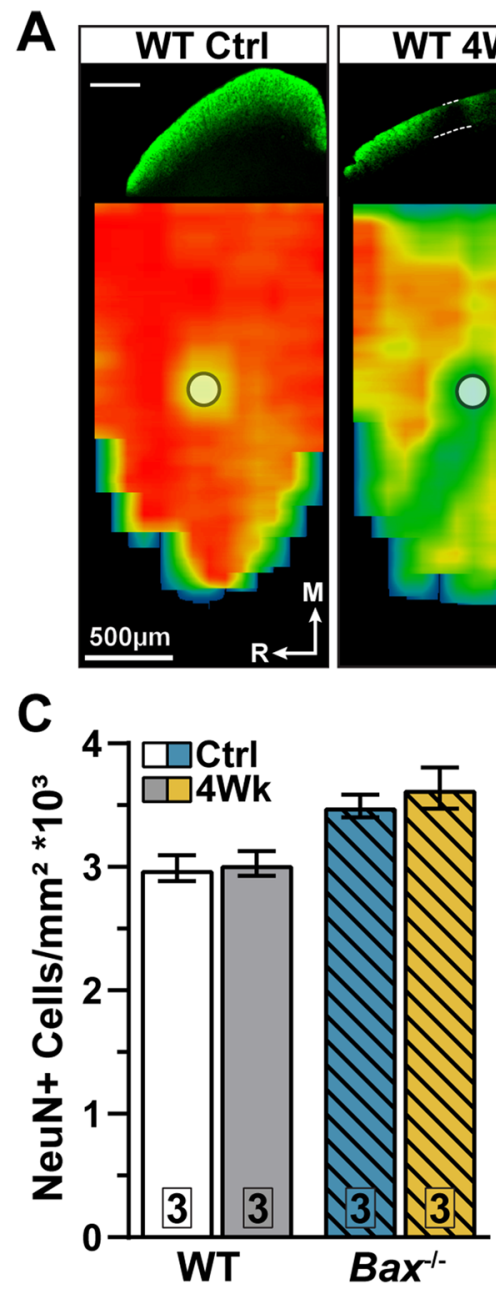
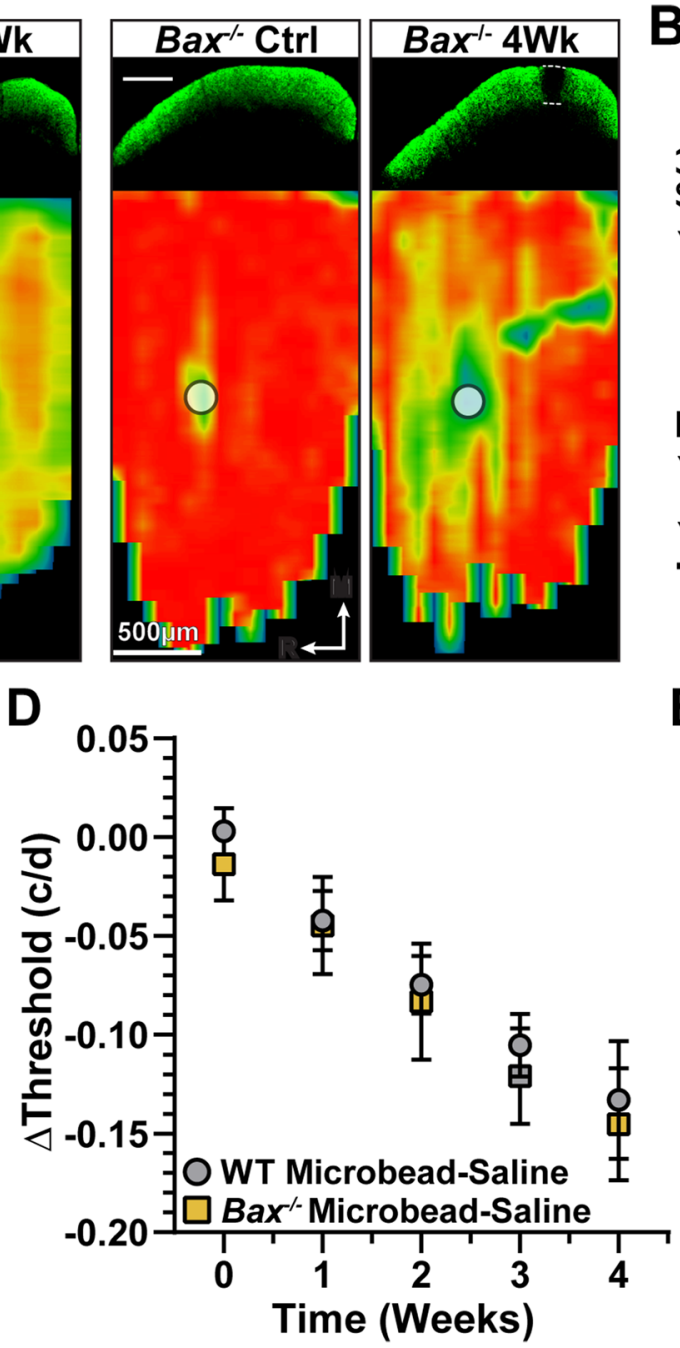

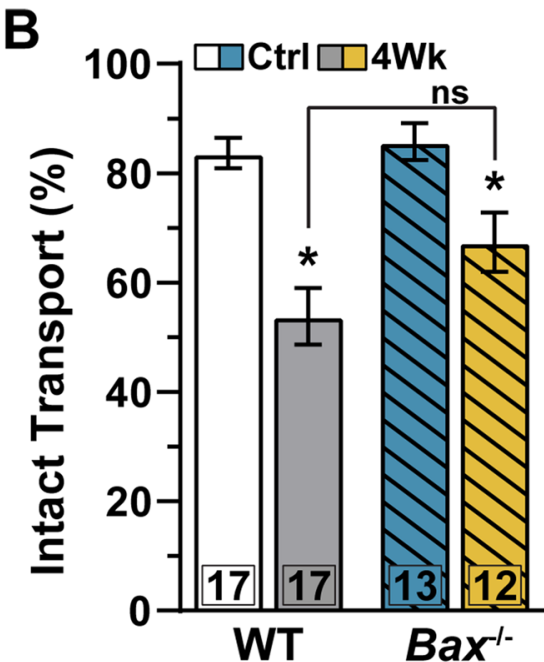

$\mathbf{E}$

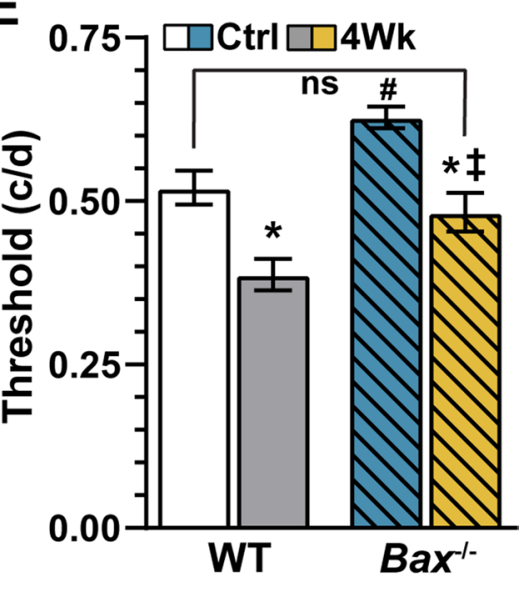

Fig. 6 IOP elevation reduces anterograde axonal transport and spatial acuity. (A, top) Representative coronal sections of the superior colliculus (SC) after intravitreal injection of CTB (green) into WT (left) and $\mathrm{Bax}^{-/-}$(right) control and 4-week microbead eyes. Scale bar $=500 \mu \mathrm{m}$. Dotted lines indicate deficits in CTB transport. (A, bottom) Example retinotopic heatmaps reconstructed from CTB intensity measurements in SC sections. Optic discs are indicated by filled white circles. Medial (M) and rostral (R) orientations are indicated. (B) IOP elevation significantly reduced anterograde axon transport of CTB in both WT $(p=0.0002)$ and $\mathrm{Bax}^{-/-}$mice $(p=0.03)$. (C) Elevating IOP did not significantly affect the density of NeuN+ cells in the SC of WT or Bax ${ }^{-/-}$mice $(p \geq 0.82)$. (D) Spatial frequency threshold (cycles/degree, c/d) of microbead minus saline injected eyes ( $\Delta$ Threshold) from WT and $B a x^{-/-}$mice 1 to 4 weeks post injection

\section{Conclusions}

Our results indicate that $B a x$ contributes to RGC dendritic degeneration and response degradation during glaucoma. In WT mice, 1 month of IOP elevation caused significant dendritic pruning and decline in responses to light in both $\alpha \mathrm{ON}-\mathrm{S}$ and $\alpha \mathrm{OFF}-\mathrm{S}$ RGCs. $\mathrm{Bax}^{-/-}$robustly reduced $(p>0.99)$. (E) $\mathrm{Bax}^{-/-}$significantly increased spatial frequency resolution (\#, $p \leq 0.03$ ). Four weeks of IOP elevation significantly reduced spatial frequency threshold in WT $(*, p=0.0009)$ and $\mathrm{Bax}^{-/-}$mice (*, $p=0.004)$. However, spatial acuity of $\mathrm{Bax}^{-/-}$microbead-injected eyes remained better than microbead-injected eyes of WT mice ( $\neq$, $p=0.05$ ) and not significantly different compared to saline-injected eyes of WTs $(p=0.73)$. Spatial frequency threshold animal numbers: baseline (time 0): WT $n=55, \operatorname{Bax}^{-1-} n=60 ; 1$ week: WT $n=37, B^{-x^{-1}}$ $n=40$; 2 weeks: WT $n=44, \operatorname{Bax}^{-/-} n=40 ; 3$ weeks: WT $n=44, B^{-1-}$ $n=40$; 4 weeks: WT $n=20, \mathrm{Bax}^{-/-} n=13$. Statistics: Kruskal-Wallis test, Dunn's post hoc (B, E), one-way ANOVA, Tukey post hoc (C), two-way repeated measures ANOVA, Tukey's post hoc (D). Data presented as mean \pm SEM.

dendritic pruning and stabilized light signaling in $\alpha \mathrm{ON}-\mathrm{S}$ and $\alpha$ OFF-S RGCs during IOP elevation. In agreement with previous studies, we found axonopathy endures during glaucoma in the absence of Bax.

Supplementary Information The online version contains supplementary material available at https://doi.org/10.1007/s12035-021-02675-5. 
Acknowledgements We thank Karis B. D'Alessandro for help with genotyping and Vincent Yao for help with data analysis.

Availability of data and materials The datasets used and/or analyzed during the current study are available from the corresponding author on reasonable request.

Author Contribution M.L.R., S.P., and N.R.M. performed the experiments. M.L.R., S.P., and N.R.M. analyzed the data. M.L.R., S.P., and D.J.C designed the research. M.L.R. and D.J.C wrote the paper. All authors read and approved the final manuscript.

Funding Support was provided by a departmental unrestricted award by the Research to Prevent Blindness Inc., Research to Prevent Blindness Inc. Stein Innovation Award, the Stanley Cohen Innovation Fund, and National Institutes of Health grants EY017427, EY024997, and EY008126 to DJC. Imaging was supported through the Vanderbilt University Medical Center Cell Imaging Shared Resource core facility and NIH grants CA68485, DK20593, DK58404, and DK59637.

\section{Declarations}

Ethics Approval and Consent to Participate The Vanderbilt University Institutional Animal Care and Use Committee approved all experimental procedures described in this manuscript.

Consent for Publication All authors have approved the contents of this manuscript and provided consent for publication.

Competing Interests The authors declare no competing interests.

Open Access This article is licensed under a Creative Commons Attribution 4.0 International License, which permits use, sharing, adaptation, distribution and reproduction in any medium or format, as long as you give appropriate credit to the original author(s) and the source, provide a link to the Creative Commons licence, and indicate if changes were made. The images or other third party material in this article are included in the article's Creative Commons licence, unless indicated otherwise in a credit line to the material. If material is not included in the article's Creative Commons licence and your intended use is not permitted by statutory regulation or exceeds the permitted use, you will need to obtain permission directly from the copyright holder. To view a copy of this licence, visit http://creativecommons.org/licenses/by/4.0/.

\section{References}

1. Maes ME, Schlamp CL, Nickells RW (2017) BAX to basics: How the BCL2 gene family controls the death of retinal ganglion cells. Prog Retin Eye Res 57:1-25

2. Nechushtan A, Smith CL, Hsu YT, Youle RJ (1999) Conformation of the Bax C-terminus regulates subcellular location and cell death. EMBO J 18(9):2330-2341

3. Wang K, Gross A, Waksman G, Korsmeyer SJ (1998) Mutagenesis of the $\mathrm{BH} 3$ domain of BAX identifies residues critical for dimerization and killing. Mol Cell Biol 18(10):6083-6089

4. Sundararajan R, Cuconati A, Nelson D, White E (2001) Tumor necrosis factor-alpha induces Bax-Bak interaction and apoptosis, which is inhibited by adenovirus E1B 19K. J Biol Chem 276(48):45120-45127
5. Zhang Z, Subramaniam S, Kale J, Liao C, Huang B, Brahmbhatt H, Condon SG, Lapolla SM, Hays FA, Ding J et al (2016) BH3in-groove dimerization initiates and helix 9 dimerization expands Bax pore assembly in membranes. EMBO J 35(2):208-236

6. Du C, Fang M, Li Y, Li L, Wang X (2000) Smac, a mitochondrial protein that promotes cytochrome c-dependent caspase activation by eliminating IAP inhibition. Cell 102(1):33-42

7. Saito M, Korsmeyer SJ, Schlesinger PH (2000) BAX-dependent transport of cytochrome $\mathrm{c}$ reconstituted in pure liposomes. Nat Cell Biol 2(8):553-555

8. Vila M, Jackson-Lewis V, Vukosavic S, Djaldetti R, Liberatore G, Offen D, Korsmeyer SJ, Przedborski S (2001) Bax ablation prevents dopaminergic neurodegeneration in the 1-methyl- 4-phenyl1,2,3,6-tetrahydropyridine mouse model of Parkinson's disease. Proc Natl Acad Sci U S A 98(5):2837-2842

9. Kudo W, Lee HP, Smith MA, Zhu X, Matsuyama S, Lee HG (2012) Inhibition of Bax protects neuronal cells from oligomeric A $\beta$ neurotoxicity. Cell Death Dis 3(5):e309

10. Reyes NA, Fisher JK, Austgen K, VandenBerg S, Huang EJ, Oakes SA (2010) Blocking the mitochondrial apoptotic pathway preserves motor neuron viability and function in a mouse model of amyotrophic lateral sclerosis. J Clin Invest 120(10):3673-3679

11. Whitmore AV, Libby RT, John SW (2005) Glaucoma: thinking in new ways-a role for autonomous axonal self-destruction and other compartmentalised processes? Prog Retin Eye Res 24(6):639-662

12. Calkins DJ (2012) Critical pathogenic events underlying progression of neurodegeneration in glaucoma. Prog Retin Eye Res 31(6):702-719

13. Williams PA, Tribble JR, Pepper KW, Cross SD, Morgan BP, Morgan JE, John SW, Howell GR (2016) Inhibition of the classical pathway of the complement cascade prevents early dendritic and synaptic degeneration in glaucoma. Mol Neurodegener 11:26

14. Libby RT, Li Y, Savinova OV, Barter J, Smith RS, Nickells RW, John SW (2005) Susceptibility to neurodegeneration in a glaucoma is modified by Bax gene dosage. PLoS Genet 1(1):17-26

15. Harder JM, Braine CE, Williams PA, Zhu X, MacNicoll KH, Sousa GL, Buchanan RA, Smith RS, Libby RT, Howell GR et al (2017) Early immune responses are independent of RGC dysfunction in glaucoma with complement component $\mathrm{C} 3$ being protective. Proc Natl Acad Sci U S A 114(19):E3839-e3848

16. Lambert WS, Ruiz L, Crish SD, Wheeler LA, Calkins DJ (2011) Brimonidine prevents axonal and somatic degeneration of retinal ganglion cell neurons. Mol Neurodegener 6(1):4

17. Beirowski B, Babetto E, Coleman MP, Martin KR (2008) The WldS gene delays axonal but not somatic degeneration in a rat glaucoma model. Eur J Neurosci 28(6):1166-1179

18. Howell GR, Libby RT, Jakobs TC, Smith RS, Phalan FC, Barter JW, Barbay JM, Marchant JK, Mahesh N, Porciatti V et al (2007) Axons of retinal ganglion cells are insulted in the optic nerve early in DBA/2J glaucoma. J Cell Biol 179(7):1523-1537

19. Williams PA, Harder JM, Foxworth NE, Cardozo BH, Cochran KE, John SWM (2017) Nicotinamide and WLD(S) act together to prevent neurodegeneration in glaucoma. Front Neurosci 11:232

20. Fernandes KA, Harder JM, John SW, Shrager P, Libby RT (2014) DLK-dependent signaling is important for somal but not axonal degeneration of retinal ganglion cells following axonal injury. Neurobiol Dis 69:108-116

21. Howell GR, Soto I, Libby RT, John SW: Intrinsic axonal degeneration pathways are critical for glaucomatous damage. Exp Neurol 2012.

22. Risner ML, Pasini S, McGrady NR, D'Alessandro KB, Yao V, Cooper ML, Calkins DJ (2021) Neuroprotection by Wld(S) depends on retinal ganglion cell type and age in glaucoma. Mol Neurodegener 16(1):36 
23. Donahue RJ, Maes ME, Grosser JA, Nickells RW (2020) BAXdepleted retinal ganglion cells survive and become quiescent following optic nerve damage. Mol Neurobiol 57(2):1070-1084

24. Calkins DJ, Lambert WS, Formichella CR, McLaughlin WM, Sappington RM (2018) The microbead occlusion model of ocular hypertension in mice. Methods Mol Biol 1695:23-39

25. Knudson CM, Tung KS, Tourtellotte WG, Brown GA, Korsmeyer SJ (1995) Bax-deficient mice with lymphoid hyperplasia and male germ cell death. Science 270(5233):96-99

26. Risner ML, McGrady NR, Boal AM, Pasini S, Calkins DJ (2020) TRPV1 supports axogenic enhanced excitability in response to neurodegenerative stress. Front Cell Neurosci 14:603419

27. Risner ML, Pasini S, Cooper ML, Lambert WS, Calkins DJ (2018) Axogenic mechanism enhances retinal ganglion cell excitability during early progression in glaucoma. Proc Natl Acad Sci U S A 115(10):E2393-e2402

28. McGrady NR, Risner ML, Vest V, Calkins DJ (2020) TRPV1 tunes optic nerve axon excitability in glaucoma. Front Physiol 11:249

29. Cooper ML, Pasini S, Lambert WS, D'Alessandro KB, Yao V, Risner ML, Calkins DJ (2020) Redistribution of metabolic resources through astrocyte networks mitigates neurodegenerative stress. Proc Natl Acad Sci U S A

30. Risner ML, McGrady NR, Pasini S, Lambert WS, Calkins DJ (2020) Elevated ocular pressure reduces voltage-gated sodium channel NaV1.2 protein expression in retinal ganglion cell axons. Exp Eye Res 190:107873

31. Crish SD, Sappington RM, Inman DM, Horner PJ, Calkins DJ (2010) Distal axonopathy with structural persistence in glaucomatous neurodegeneration. Proc Natl Acad Sci U S A 107(11):5196-5201

32. Fischer RA, Risner ML, Roux AL, Wareham LK, Sappington RM (2019) Impairment of membrane repolarization accompanies axon transport deficits in glaucoma. Front Neurosci 13:1139

33. Harder JM, Libby RT (2011) BBC3 (PUMA) regulates developmental apoptosis but not axonal injury induced death in the retina. Mol Neurodegener 6:50

34. El-Danaf RN, Huberman AD (2015) Characteristic patterns of dendritic remodeling in early-stage glaucoma: evidence from genetically identified retinal ganglion cell types. J Neurosci 35(6):2329-2343

35. Ou Y, Jo RE, Ullian EM, Wong RO, Della Santina L (2016) Selective vulnerability of specific retinal ganglion cell types and synapses after transient ocular hypertension. J Neurosci 36(35):9240-9252

36. Della Santina L, Inman DM, Lupien CB, Horner PJ, Wong RO (2013) Differential progression of structural and functional alterations in distinct retinal ganglion cell types in a mouse model of glaucoma. J Neurosci 33(44):17444-17457

37. Bleckert A, Schwartz GW, Turner MH, Rieke F, Wong RO (2014) Visual space is represented by nonmatching topographies of distinct mouse retinal ganglion cell types. Curr Biol 24(3):310-315

38. Sankaran M, Keeley PW, He L, Iuvone PM, Reese BE (2018) Dopaminergic amacrine cell number, plexus density, and dopamine content in the mouse retina: strain differences and effects of Bax gene disruption. Exp Eye Res 177:208-212

39. Calkins DJ: Adaptive responses to neurodegenerative stress in glaucoma. Prog Retin Eye Res 2021:100953.

40. Mosinger Ogilvie J, Deckwerth TL, Knudson CM, Korsmeyer SJ (1998) Suppression of developmental retinal cell death but not of photoreceptor degeneration in Bax-deficient mice. Invest Ophthalmol Vis Sci 39(9):1713-1720

41. Ward NJ, Ho KW, Lambert WS, Weitlauf C, Calkins DJ (2014) Absence of transient receptor potential vanilloid-1 accelerates stress-induced axonopathy in the optic projection. J Neurosci 34(9):3161-3170
42. Jiao S, Li Z (2011) Nonapoptotic function of BAD and BAX in long-term depression of synaptic transmission. Neuron 70(4):758-772

43. Ertürk A, Wang Y, Sheng M (2014) Local pruning of dendrites and spines by caspase-3-dependent and proteasome-limited mechanisms. J Neurosci 34(5):1672-1688

44. D'Amelio M, Cavallucci V, Cecconi F (2010) Neuronal caspase-3 signaling: not only cell death. Cell Death Differ 17(7):1104-1114

45. Li Z, Okamoto K, Hayashi Y, Sheng M (2004) The importance of dendritic mitochondria in the morphogenesis and plasticity of spines and synapses. Cell 119(6):873-887

46. Hyman BT, Yuan J (2012) Apoptotic and non-apoptotic roles of caspases in neuronal physiology and pathophysiology. Nat Rev Neurosci 13(6):395-406

47. Hollville E, Deshmukh M (2018) Physiological functions of nonapoptotic caspase activity in the nervous system. Semin Cell Dev Biol 82:127-136

48. Williams DW, Kondo S, Krzyzanowska A, Hiromi Y, Truman JW (2006) Local caspase activity directs engulfment of dendrites during pruning. Nat Neurosci 9(10):1234-1236

49. Garzón F, Coimbra D, Parcerisas A, Rodriguez Y, García JC, Soriano E, Rama R (2018) NeuroEPO Preserves Neurons from Glutamate-Induced Excitotoxicity. J Alzheimers Dis 65(4):1469-1483

50. Stevens B, Allen NJ, Vazquez LE, Howell GR, Christopherson KS, Nouri N, Micheva KD, Mehalow AK, Huberman AD, Stafford B et al (2007) The classical complement cascade mediates CNS synapse elimination. Cell 131(6):1164-1178

51. Kaur A, Sultan SH, Murugaiah V, Pathan AA, Alhamlan FS, Karteris E, Kishore U (2016) Human C1q Induces Apoptosis in an Ovarian Cancer Cell Line via Tumor Necrosis Factor Pathway. Front Immunol 7:599

52. Jones RS, Carroll RC, Nawy S (2012) Light-induced plasticity of synaptic AMPA receptor composition in retinal ganglion cells. Neuron 75(3):467-478

53. Kirkland RA, Franklin JL (2015) Bax and caspases regulate increased production of mitochondria-derived reactive species in neuronal apoptosis: LACK of A role for depletion of cytochrome $\mathrm{c}$ from the mitochondrial electron transport chain. Biochem Biophys Rep 4:158-168

54. Kirkland RA, Saavedra GM, Cummings BS, Franklin JL (2010) Bax regulates production of superoxide in both apoptotic and nonapoptotic neurons: role of caspases. J Neurosci 30(48):16114-16127

55. Oddone F, Roberti G, Micera A, Busanello A, Bonini S, Quaranta L, Agnifili L, Manni G (2017) Exploring serum levels of brain derived neurotrophic factor and nerve growth factor across glaucoma stages. PLoS One 12(1):e0168565

56. Harris MH, Vander Heiden MG, Kron SJ, Thompson CB (2000) Role of oxidative phosphorylation in Bax toxicity. Mol Cell Biol 20(10):3590-3596

57. Patel MY, Stovall K, Franklin JL (2020) The intrinsic apoptotic pathway lies upstream of oxidative stress in multiple organs. Free Radic Biol Med 158:13-19

58. Kernell D (1966) Input resistance, electrical excitability, and size of ventral horn cells in cat spinal cord. Science 152(3729):1637-1640

59. Lee SC, Cowgill EJ, Al-Nabulsi A, Quinn EJ, Evans SM, Reese BE (2011) Homotypic regulation of neuronal morphology and connectivity in the mouse retina. J Neurosci 31(40):14126-14133

60. Keeley PW, Lebo MC, Vieler JD, Kim JJ, St John AJ, Reese BE (2021) Interrelationships between cellular density, mosaic patterning, and dendritic coverage of VGluT3 amacrine cells. J Neurosci 41(1):103-117

Publisher's Note Springer Nature remains neutral with regard to jurisdictional claims in published maps and institutional affiliations. 